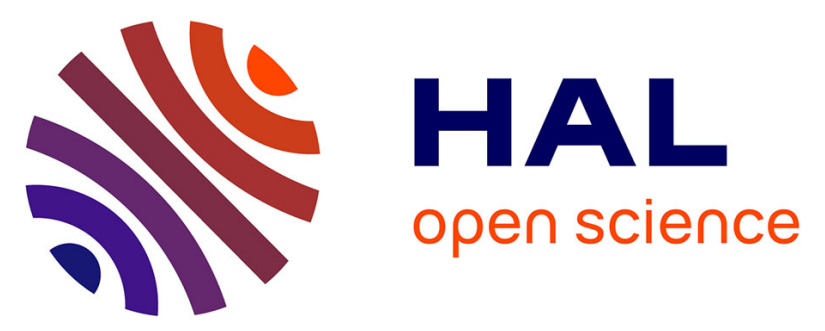

\title{
A neuronal migratory pathway crossing from diencephalon to telencephalon populates amygdala nuclei
} Fernando García-Moreno, María Pedraza, Luca Giovanni Di Giovannantonio, Michela Di Salvio, Laura Lopez-Mascaraque, Antonio Simeone, Juan Andrés de Carlos

\section{To cite this version:}

Fernando García-Moreno, María Pedraza, Luca Giovanni Di Giovannantonio, Michela Di Salvio, Laura Lopez-Mascaraque, et al.. A neuronal migratory pathway crossing from diencephalon to telencephalon populates amygdala nuclei. Nature Neuroscience, 2010, 10.1038/nn.2556 . hal-00538625

\section{HAL Id: hal-00538625 \\ https://hal.science/hal-00538625}

Submitted on 23 Nov 2010

HAL is a multi-disciplinary open access archive for the deposit and dissemination of scientific research documents, whether they are published or not. The documents may come from teaching and research institutions in France or abroad, or from public or private research centers.
L'archive ouverte pluridisciplinaire HAL, est destinée au dépôt et à la diffusion de documents scientifiques de niveau recherche, publiés ou non, émanant des établissements d'enseignement et de recherche français ou étrangers, des laboratoires publics ou privés. 


\section{Title}

\section{A neuronal migratory pathway crossing from diencephalon to telencephalon populates amygdala nuclei}

Abbreviated title: Otp in the development of the amygdala

\section{Authors}

Fernando García-Moreno ${ }^{1}$, María Pedraza ${ }^{1}$, Luca G. Di Giovannantonio ${ }^{2}$, Michela Di Salvio $^{2}$, Laura López-Mascaraque ${ }^{1}$, Antonio Simeone ${ }^{2,3,4}$ \& Juan A. De Carlos ${ }^{1}$

${ }^{1}$ Cajal Institute (CSIC). Laboratory of Telencephalic Development; Molecular, Cellular and Developmental Neurobiology Department. Av. Doctor Arce 37, 28002 - Madrid (Spain)

${ }^{2}$ CEINGE Biotecnologie Avanzate and ${ }^{3}$ SEMM European School of Molecular Medicine. Via Comunale Margherita 482, 80145 - Naples (Italy)

${ }^{4}$ Institute of Genetics and Biophysics "A. Buzzati-Traverso", CNR. Via P. Castellino 111, 80131 - Naples (Italy)

Corresponding author: Juan A. De Carlos; decarlos@cajal.csic.es;

Phone number: 9158547 07; fax number: 915854754

Number of figures and tables: 8 color figures

Contents of supplemental material (if applicable): 11 figures, 1 video, 1 table

Keywords: tangential migration; hypothalamus; amygdaloid nucleus; stria terminalis 


\section{Abstract}

Neurons usually migrate and differentiate within one particular encephalic vesicle. Here we describe a murine population of diencephalic neurons that colonize the telencephalic amygdaloid complex, migrating along a tangential route that crosses a boundary between developing brain vesicles. The diencephalic transcription factor OTP is necessary for this migratory behavior. 
The amygdala is a functionally and structurally heterogeneous complex of nuclei ${ }^{1}$ located in the ventro-caudal telencephalon that fulfils a primary role in processing and the memory of emotional reactions. Based on structural, functional and developmental features, the amygdala is divided into four groups of nuclei, together with a rostro-medial extension called the extended amygdala that includes the bed nuclei of the stria terminalis (BST) and the substantia innominata ${ }^{2-4}$. Attending to their embryological origin, the amygdala consists of two groups of nuclei ${ }^{5,6}$ that arise from pallial ${ }^{7-10}$ and subpallial ${ }^{11-14}$ compartments, although some amygdaloid nuclei are of mixed developmental origin. The medial amygdaloid nucleus (MeA) that forms the vomeronasal amygdala, along with the posterior-medial cortical amygdaloid nucleus (PMc), express genes typical of both telencephalic subdivisions and they receive cells from each component ${ }^{11,15,16}$. Moreover, the expression of certain diencephalic genes, like Orthopedia ${ }^{17,18}\left(\right.$ Otp), Single disabled-mind $1^{19}(\operatorname{Sim} 1)$ and Brain- $2^{20}(B r n 2)$ suggests that some amygdaloid nuclei have a dual prosencephalic origin ${ }^{14,21-23}$.

Otp is a highly conserved gene encoding a homeodomain transcription factor specifically associated with the development of the hypothalamus in vertebrates ${ }^{18,24}$. Otp plays essential roles in the differentiation of neuroendocrine hypothalamic neurons associated with the paraventricular hypothalamic (PVH) and supraoptic nuclei ${ }^{17,26,27}$ (SO). However, since such neurons are absent from amygdaloid nuclei, Otp might play a different role in this system. It is not clear if OTP-expressing cells can reach telencephalic structures from their origins in diencephalic germinative zones or alternatively, whether these cells are originally telencephalic and they simply express OTP once they become independent of the hypothalamus.

We examined the development of the telencephalic OTP-expressing cell population to test the possibility that cells generated in the hypothalamus colonize the telencephalon. We describe a novel route of tangential cell migration whereby cells expressing OTP transgress the di-telencephalic junction (DTJ). Subsequently, we used different in utero approaches to determine whether OTP-expression was necessary for these cells to migrate toward their targets. The cells that migrate along this pathway originate exclusively in the rostro-dorsal hypothalamic ventricular zone and they are destined to several amygdaloid nuclei. These diencephalic migratory cells express OTP and they are spatially related to the stria terminalis. Moreover, when OTP-expression is silenced in hypothalamic cells they no longer colonize the amygdala as they fail to migrate along this pathway, as evident in Otp ${ }^{-1}$ mice. Thus, our data show that some amygdaloid nuclei are composed of a complex mixture of cells of diencephalic-telencephalic origin, identifying the migratory pathway followed by hypothalamic neurons to reach these nuclei and a transcription factor that controls this process.

\section{Results}

\section{OTP-expression during development}

Orthopedia gene is believed to be exclusively involved in the development of the hypothalamic neuroendocrine lineage ${ }^{25}$. Here, we have studied the spatiotemporal expression of murine OTP-protein during embryonic brain development, finding that the OTP-protein was 
first detected at E10 exclusively in the ventral diencephalon and particularly, in the mantle of the dorsal and ventral hypothalamic areas (Fig. 1a-c). These domains probably belong to the PVH (Fig. 1b) and the ventro-medial hypothalamic nucleus (VMH; Fig. 1c), respectively. At E11, a similar pattern of OTP-expression was detected in the hypothalamus, together with some labeling at the DTJ (Fig. 1d-g). Indeed, several OTP-immunoreactive (OTP-ir) cells were located at the boundary between both vesicles (Fig. 1f,g), suggesting that the cells generated earlier had migrated from the hypothalamus towards the telencephalon. As development progressed, the OTP-ir cells number increased and at E12 (Fig. 1h-j), a continuous stream of OTP-ir cells formed a pathway from the hypothalamus (Fig. 1h,i) to the caudo-ventral telencephalic area. In addition, OTP-ir cells were evident in the amygdaloid primordia (Fig. 1j).

The definitive pattern of OTP-ir was evident at the middle and final stages of embryonic development (Fig. 1k-y), and many OTP-ir hypothalamic cells at E15 (Fig. 1k-r) persisted until the end of the process (Fig. 1s,t). These cells were located in the early hypothalamic nuclei, particularly the PVH (Fig. 1l,n,s,t), the SO (Fig. 1n,s; which probably derives from the ventricular zone of the paraventricular hypothalamic nucleus ${ }^{29-31}-\mathrm{vzPVH}$ ), and the VMH (Fig. 1n). OTP-expression in the PVH defined a continuous band of cells that entered the telencephalon (Fig. 1I), a pattern that persisted throughout development. OTP-ir cells were also found in the BST, which lie lateral and dorsal to the PVH (Fig. $1 \mathrm{k}, \mathrm{l}, \mathrm{t}, \mathrm{u}$ ), as well as close to the supracapsular nucleus of the BST (BST-sc; Fig. 1l,o-r,v,w). Finally, OTP-expression was evident ventral to the BST-sc, entering the vomeronasal amygdala (Fig. $1 \mathrm{~m}, \mathrm{n}, \mathrm{s}, \mathrm{x}, \mathrm{y}$ ), where we found OTP-ir cells in the MeA and in the PMc.

There was a similar expression pattern during early postnatal development. However, we never found OTP in adults, although it was not possible to determine when its expression was shut-off in the cells that expressed this factor previously. Since the number of OTP-ir cells clearly increased from early stages of embryonic development (Fig. 1a-j), we performed birthdating studies to define the temporal limits of OTP-ir cell generation, that it was completely finished at E13. Indeed, BrdU-cells generated at E13 did not express OTP at E18, neither in the hypothalamic nor amygdaloid regions (Supplementary Figure 1). Thus, OTP-ir cells appeared to be generated between E10 and E12.

\section{Characterization of OTP-ir cells}

Otp is associated with the development of diencephalic dopaminergic neurons ${ }^{28}$, although TH immunohistochemistry indicated that the OTP-telencephalic neurons we identified were not dopaminergic at E18 (Supplementary Figure 1). Further, we examined transgenic GAD-GFP mice that express GFP under the control of the GAD promoter, such that almost every GABAergic cell expresses GFP. Immunohistochemistry against OTP in transgenic GAD67 isoform showed no colocalization at E13 (Supplementary Figure 1) nor at E15 (data not shown), showing that OTP-cell populations were not GABAergic.

We studied the hormones expressed in the PVH resulting that none of the most common hormones found in the hypothalamus were expressed by OTP-cells, including Somatostatin (SS), Corticotropin-Releasing Hormone (CRH), Choline Acetyltransferase (ChAT), Oxytocin (OT), Arginine Vasopressin (AVP), Thyrotropin-Releasing Hormone (TRH) and Growth-HormoneReleasing Hormone (GHRH; Supplementary Figure 1). We also studied three specific transcription factors (Foxg1, Meis2 and Zic1) expressed in some OTP areas (hypothalamic and amygdaloid). In Otp ${ }^{+/}$embryos, these factors were co-expressed with OTP in the BST and POA 
(Fig. 2a-h) while only Foxg1 and Meis2 were co-expressed with OTP in the MeA (Fig. 2a-h). Although the neurotransmitter identity of these OTP-amygdaloid cells remained unclear, the OTP-cells in the MeA appeared to be glutamatergic since the vesicular glutamate transporter vGLUT2 was identified around the nucleus (Fig. 2i-m).

To define the cell types differentiated from OTP-neuroblasts migrating from the $\mathrm{PVH}, \mathrm{a}$ GFP plasmid was electroporated into the third ventricle of E11 embryos in utero. When these embryos were sacrificed on postnatal day $(P)$ 15, a heterogeneous population of stellate and bitufted GFP-neurons was identified in the MeA and PMc nuclei. Since these neurons were multipolar, radiating several long dendrites with few spines in all directions (Fig. $2 n-0$ ), they are likely to be projecting cells. Furthermore, similar neurons were identified in X-Gal cells in MeA of $\mathrm{Otp}^{+/-}$P15 mice injected with Lucifer Yellow (Fig. 2p,q). The existence of these cell types in the amygdaloid nuclei was confirmed in young adult mice stained by the Golgi method (Fig. 2r-u).

\section{Diencephalic cells colonize the telencephalon}

Our findings led to the possibility that some diencephalic-derived cells migrate toward the telencephalon and locate close to the axonal pathway formed by the stria terminalis (Fig. 1). Hence, we traced the diencephalic cell lineage at E12 by injecting in utero the CFDA dye into the third ventricle, allowing them to survive until E18. Then, fixed brains were Dil labeled to also reveal the stria terminalis (Supplementary Figure 3).

Injections into the third ventricle labeled many diencephalic cells corresponding to thalamic and hypothalamic cells. A further cell population appeared to arrive at the level of the BST and BST-sc, indicating that some diencephalic cells colonize these telencephalic nuclei. Moreover, CFDA-labeled cells were spatially related to the stria terminalis. Diencephalic cells were always located medially to the axonal pathway, defining a boundary between the amygdaloid axons and the thalamic region. This medial location was similar to that found for the OTP-ir cells in the BST-sc (Supplementary Figure 3).

\section{Neuronal migration from the vzPVH}

A series of experiments were designed to define the precise origin of the OTP-ir telencephalic cells by tracing cell populations labeled in utero or exo utero injection. The pattern of OTP-expression suggested that migratory cells originate at the level of the PVH (Fig. 11) and therefore, CFDA was injected into the hypothalamic ventricular zone at E10 and E11, close to the PVH (vzPVH; Supplementary Figure 4). After 24 hours in culture, labeled cells were seen to migrate dorsally and follow a tangential path towards more rostral levels. The cells generated early in the $\mathrm{VzPVH}$ initially migrated radially to cover the hypothalamic area, before these OTP-ir cells began migrating towards the dorsal hypothalamic regions. Finally, these cells entered the telencephalon and they colonized more rostral territories in the mantle of the medial and caudal ganglionic eminences. Telencephalic cells from the vzPVH labeled with tracer appeared to lie in areas of OTP-expression and they expressed OTP. These data show that at least, one hypothalamic proliferative region, the $\mathrm{vzPVH}$, gave rise to a telencephalic OTP-ir population (Supplementary Figure 4).

Tracer injections were repeated in utero aided by ecographic ultrasound to trace selective diencephalic cell lineages and to define the final destination of the OTP-ir telencephalic cells. The migration and final location of these cells were studied at the mid- and final stages of 
embryonic development (E15 and E18; Figs. 3 and 4, respectively). The destination of the VzPVH-generated cells reflected the pattern of OTP-expression (Fig. 3a-c; 4a,b) at both stages. The tangential migration revealed the complex telencephalic peak of OTP-expression. Firstly, cells settled in the PVH and BST to subsequently populate territories more dorsal to the BST (Fig. 3g,h; 4c-g). Calbindin (CB) is abundantly expressed in the BST territory, especially in the BST-sC and PVH, although VzPVH-generated cells that colonized this area never expressed this protein (Fig. 3d,e,i; 4g,h). At levels caudal to the injection site, some traced cells were associated to the stria terminalis (Fig. 3e,f,i-l; 4h,i), like those defined by OTP immunohistochemistry (Fig. 10-r,v,w), although these cells did not express calretinin (CR; Fig. $3 \mathrm{j} ; 4 \mathrm{i})$. The most distant area colonized by diencephalic cells was the vomeronasal amygdala. Labeled cells were found ventral to the course of the stria terminalis, specifically occupying the MeA and PMc nuclei (Fig. 3f,k,l; 4j-o). It was notable that diencephalic-generated cells did not colonize other amygdaloid nuclei. Moreover, these migratory cells never expressed the pallial marker Tbr1 (Fig. 4m-o).

To finally demonstrate the diencephalic origin of the OTP-telencephalic cells, dual immunohistochemistry was performed with this transcription factor. Almost all of the diencephalic cells that settled in the telencephalon expressed OTP (Fig. 5), with a constant colocalization of markers along the entire migratory pathway. Thus, diencephalic migratory cells were seen to express OTP at the hypothalamic levels (Fig. 5a-c), along the caudo-rostral extension of the BST (Fig. 5d-i) and in the nuclei of the vomeronasal amygdala (Fig. 5j-I).

These results confirm that the VzPVH is an important hypothalamic region that gives rise to a tangential migratory cell population that crosses the boundary between prosencephalic vesicles. These early generated diencephalic glutamatergic neurons express OTP.

\section{Neuronal migration from adjacent proliferative zones}

When other diencephalic germinative zones were studied, intrauterine tracer injections failed to identify telencephalic colonization. Hence, the vzPVH appears to be the sole germinative diencephalic region contributing to amygdaloid development. Ecographic ultrasonic guided injections of tracers into the most ventral thalamic ventricular region (vzTh), just above the diencephalic sulcus and the $\mathrm{vzPVH}$, gave rise to some radially migrating cell populations that reach ventro-lateral thalamic nuclei. The cells following this radial migratory path bordered the thalamic-hypothalamic and thalamic-telencephalic boundaries, clearly delimited by CB and OTP immunoreactivity. As expected, thalamic-derived migratory cells did not cross these boundaries or express OTP (Supplementary Figure 5).

Injections into the caudal hypothalamic germinative zone (vzHTc) also labeled cells that migrated radially into hypothalamic territories. These cells migrated to settle in hypothalamic domains associated with the nigro-striatal pathway and the medial prosencephalic tract. They never migrated towards the amygdaloid nuclei and some of them appeared in the $\mathrm{VMH}$ and in the caudal portion of the PVH; however, these cells did not express OTP (Supplementary Figure $6)$.

\section{Neuronal migration from vzPVH lacking OTP-expression}

We shifted our interest to the migratory cell mechanisms by analyzing whether OTP might play novel roles when strongly expressed in vzPVH-derived cells. We studied the function of OTP by inhibiting its translation by RNA interference (RNAi), transfecting diencephalic cells 
with a plasmid that encoded a specific RNAi (shRNA + pCAGGS/eGFP). Transfections were performed by in utero electroporation at $\mathrm{E} 10$, having filled the third ventricle with a mixture of the recombinant plasmids. The functional analysis was carried out by comparing these cells expressed the functional with control cells transfected with a non-specific vector that did not silence any gene.

Cells transfected with shRNA-Otp had strongly downregulated OTP-expression at E18 (Fig. 6) and indeed, this in vivo approach reduced the proportion of cells expressing OTP to $17.7 \%$ of GFP-cells expressing OTP in the control embryos. Hypothalamic cells lacking OTP at E10 clearly adopted a different location at E18 (Fig. 6) and the normal distribution of these cells in the brain was clearly altered (compare Fig. $6 \mathrm{~b}$ to $\mathrm{h}$ : $\mathrm{n}=4$ control animals and 4 silenced animals). There was a marked increase in the number of transfected cells that remained at hypothalamic levels ( $31.72 \pm 4.31 \%$ s.e.m. vs. $71.53 \pm 4.08 \%$ s.e.m.; $p=0.0026$; Fig. $6 c, i, p)$, which was accompanied by a significant decrease in the number of transfected cells that colonized the BST $(24.07 \pm 2.05 \%$ s.e.m. vs. $6.567 \pm 1.95 \%$ s.e.m.; $p=0.0035$ : Fig. $6 d, j, p)$ and vomeronasal amygdala $(44.21 \pm 2.67 \%$ s.e.m. vs. $21.90 \pm 2.15 \%$ s.e.m.; $p=0.0029$ : Fig. $6 e, k, f, l, p)$. This defective migration notably decreased the number of cells that reached the $\mathrm{MeA}$, an important destination in the control embryos (Fig. 6f,I). There were more silenced cells at hypothalamic levels (Fig. $6 \mathrm{~m}$ ) and fewer at the telencephalic levels (Fig. 6n,o), further evidence that OTP is necessary for migration towards amygdaloid destinations. GFP-cells in the OTP-ir amygdaloid area in control and silenced embryos might originate from other secondary electroporation, especially subpallial electroporation. Indeed, the remarkably decrease in BST transfected cells suggested that the proportion of amygdaloid GFP-cells might be overestimated due to the inclusion of some subpallial transfected cells. Nevertheless, these data strongly suggest that OTP-expression is necessary for the correct migration of diencephalic-derived cells towards telencephalic territories.

We confirmed that silencing OTP-expression affected migration and not other processes that might reduce cell number. The transfected hemispheres did not present any significant variation in cell death when assessed by TUNEL. Moreover, when compared to their contralateral hemispheres, no significant variation in diencephalic cell death was found in either the short- (E11-E13) or long-term (E10-E18; Supplementary Figure 7). In addition, phospho-histone $3(\mathrm{p}-\mathrm{H} 3)$ immunohistochemistry demonstrated that silencing OTP-expression did not affect proliferation in silenced (84.73 \pm 9.04 s.e.m.) and non-silenced diencephalic hemispheres ( $84.33 \pm 9.20$ s.e.m. $p$-H3-ir cells; $n=4$; Supplementary Figure 7 ). Therefore, the loss of GFP-expressing cells in the telencephalon was not due to abnormalities in the proliferation of diencephalic cells.

These experiments revealed that OTP is strictly necessary to drive one or several hypothalamic-generated cell populations toward the telencephalon. In addition, OTP does not appear to take part in other developmental processes, such as proliferation and cell death.

\section{Otp-knockout mice}

To validate our findings with RNAi silencing, we studied embryos from Otp ${ }^{\text {LacZ }}$ null mutant mice ${ }^{27}$. In Otp ${ }^{-1-}$ E15 and E18 embryos, there was a strong reduction in the telencephalic expression of LacZ in the SO, BST, MeA and PMc when compared to the Otp ${ }^{+-}$controls, concomitant with a disorganization of OTP-cells in the hypothalamus (Fig. 7a-I). Moreover, these amygdaloid nuclei were smaller in the mutant embryos (Supplementary Figure 8). To 
better understand these amygdaloid abnormalities we studied additional markers that identify different structures (Fig. 8). Specific antibodies against Tbr1, Lhx1, Lhx5 and Lhx6 were employed on $\mathrm{Otp}^{+/-}$and $\mathrm{Otp}^{-/-}$mice, as they revealed useful for our purposes ${ }^{11,12,32,42}$. We found that the Lhx5 immunoreactive amygdaloid population was lost in the mutant (Fig. 8g-l,y-ad and Supplementary Figure 9). $\beta$-Gal staining colocalizes with Lhx5 at all the levels of the migratory pathway. The amygdaloid complex does not express Lhx1 at E15 nor at E18 (Fig. 8s-x and Supplementary Figure 9). The basomedial amygdaloid nucleus (BM) presented two alterations: a ventral expansion of the Tbr1 expression in E15, but E18 (Fig. 8c-d). However, hypothalamic and telencephalic Lhx6 expression is normal in the mutant (Fig. 8m-r and Supplementary Figure 9) except for some cells at the BST.

The expression patterns of Foxg1, Meis2 and Zic1 in E18 were heavily disturbed (Supplementary Figure 2). The expression of these factors was apparently unaffected in OTP null neurons.

$\operatorname{Sim} 1$ is a gene related to the neuroendocrine lineage that acts in parallel to $O t p^{25}$. The distribution of SIM1 appeared modified in at least three cell populations in Otp ${ }^{-/}$mice (Fig. $7 \mathrm{~m}$ aj). One population, only expressing OTP, did not reach its amygdaloid destinations (BST, MeA and PMc) while a second population, expressing both OTP and SIM1 and establishing cells in the BST, disappeared in the mutant. A third population, only expressing SIM1 and establishing cells surrounding the central $(\mathrm{CeA})$ and the $\mathrm{BM}$, disappeared in the Otp ${ }^{-/-}$mice. However, a population of cells only expressing SIM1 that colonized the CeA remained unaffected in the absence of OTP.

We assessed whether the OTP-cells associated to the stria terminalis and those that populate the BST-sc are necessary for the growth and guidance of the amygdaloid axons (eg. preventing their erroneous invasion of the thalamus). When the stria terminalis was Dil traced in $\mathrm{Otp}^{-/}$mice it formed clearly and completely, with no erroneous invasion of neighboring territories (Supplementary Figure 10). 


\section{Discussion}

Here we define a tangential migration of cells generated in the diencephalon that colonize the telencephalic amygdaloid complex. This is the first description of a neuronal migratory route that crosses the boundaries between different vesicles. We propose a role for the OTP transcription factor as a fundamental regulator of this novel tangential migration. In vivo short and long-term studies on whole embryos demonstrated the 3-dimensional migratory route and delineated the mechanisms governing this migration.

\section{Hypothalamic cells cross the DTJ and colonize the amygdala}

A general feature thought to govern brain development is that neurons originate, migrate and differentiate in a specific encephalic vesicle. Here we describe a novel tangential migration from the diencephalic germinative zone to the telencephalic mantle in rodents, showing that cells generated in the specific diencephalic germinative zone (vzPVH) specifically target telencephalic amygdaloid nuclei (BST, MeA, PMc). Tangential migration is thought to increase phenotypic variation by allowing progenitors to differentiate in diverse molecular environments. Thus, migration across encephalic vesicle boundaries further multiplies the molecular environments available, finally generating new cell types. Inter-vesicular tangential migration has been described previously ${ }^{33}$, such as the migration that leads to the colonization of the thalamus in humans from the telencephalic ganglionic eminences. The migratory derivatives of these subpallial structures are well known ${ }^{33-38}$, although it is believed that no such migration occurs in other mammals, like primates or rodents. Other examples of diencephalic-telencephalic migration have been recently suggested by genetic fate mapping of the Foxb1 cell lineage ${ }^{39}$. Although those data support a novel migratory route from the dorsal diencephalon (prethalamus) to the medial cerebral cortex, this population is still to be fully characterized. A similar diencephalic-telencephalic relationship to that shown here was proposed previously ${ }^{40}$, although the specific diencephalic origin of the amygdaloid cells could not be confirmed.

\section{Amygdaloid nuclei are of mixed developmental origin}

Diencephalic-telencephalic migration implies that some telencephalic nuclei possess cells that originate in the diencephalon. We demonstrate that the MeA and PMc have a mixed developmental origin, indicating that the amygdaloid complex is not exclusively telencephalic. Many authors distinguish two main subdivisions in the amygdala on the basis of the embryonic origin of their cells: the PMc belongs to the pallial amygdala ${ }^{7,8,10}$ and MeA to the subpallial amygdala ${ }^{11-15}$. Furthermore, the MeA nucleus receives cells from the ganglionic eminences and a GABAergic population from the preoptic area ${ }^{39}$, although it also expresses some pallial genes $^{10,42}$, suggesting that it also receives cells from the pallium. The cell population identified here originates in the hypothalamic area and settles in these amygdaloid nuclei, and it is glutamatergic, despite not expressing Tbr1 and not having a pallial origin. In addition, their general morphology and the presence of sparse dendritic spines suggest that these are projecting cells. The complex connections of these nuclei with many areas made it impossible to elucidate the targets of the OTP-amygdaloid population. However, structures formed by cells generated in different areas, which increases developmental complexity, also occurs in structures like the olfactory cortex ${ }^{43}$, hippocampus or cerebral cortex ${ }^{39}$. 
Similarities in the hodology, structure, neuronal morphology and biochemistry between the amygdala, and BST and substantia innominata have been found ${ }^{2-4}$. These latter two structures are thought to belong to the extended amygdala. It is known that the BST and substantia innominata are mainly subpallial in origin but we show here that, like the amygdala, they also contain diencephalic cells. Hence, these new developmental features strongly support the concept of an extended amygdala.

\section{OTP expression is needed for proper amygdaloid development}

We have shown that some amygdaloid cells must express OTP to migrate through the ditelencephalic junction. OTP is important for the differentiation of the neuroendocrine hypothalamic lineage $\mathrm{e}^{17,24-26}$ and a role in migration has not previously been proposed. Furthermore, there is no information about the telencephalic population in the Otp-knockout, although we unequivocally show that these cells need OTP to migrate across this brain boundary and for the correct formation of the MeA and PMc, as shown by the lack of Lhx5 and Lhx2 in the mutant, proteins that identify several amygdaloid structures ${ }^{11,12,32,42}$. These data suggest that OTP directly or indirectly may regulate Lhx5 and Lhx2 expression.

Sim1 is another gene that regulates the neuroendocrine lineage ${ }^{25}$, and OTP and SIM1 share a similar distribution in the telencephalic population. Both factors can be expressed independently in the same cell, and the expression of each remains unaffected in the knockout of the other ${ }^{17,44}$. Indeed, the telencephalic SIM1-expression remains unaltered in absence of OTP ${ }^{17}$. However, while a SIM1-population exists that is not affected by the absence of OTP, another two populations expressing SIM1 in the amygdaloid area appear to be modified by the absence of OTP. One such population also expresses OTP and could be related to the small Lhx2 immunoreactive group of cells at the BM but the other, although modified in its absence, does not, suggesting that a population of OTP-cells is directly implicated in the migration of another cell population that expresses SIM1. This absence of SIM1 at the BM could be related to the transient increase of the Tbr1 labeling.

While the expression of OTP is relevant in the development of the amygdaloid complex, this transcription factor is not necessary for the correct formation of the stria terminalis. While the growth of the stria terminalis is associated to several cell groups belonging to the BST and BST-SC, and the OTP-population of these nuclei is not involved in stria terminalis development, we do not discard the possibility that other populations exist in these nuclei that are directly implicated in stria terminalis formation.

In summary, we highlight the relevance of a novel migratory route whereby tangentially migratory cells settle in distinct encephalic vesicles. Mixed developmental origins would not only increase the phenotypic variability of amygdaloid nuclei but it would also make them functionality more complex. Taking into account that migrating neurons frequently transgress theoretical anatomical frontiers, it is necessary to systematically study the cellular relationships between different vesicles to finally unravel the complexity of the brain. In this sense, we propose that the inter-vesicular migration we present here is a common feature of all tetrapods, since a telencephalic OTP-ir cell population has been shown to exist in all animals studied $^{18}$, including the frog, axolotl (amphibian), chicken (bird), mouse or human (mammal). 


\section{Acknowledgments}

We thank Juan Lerma, Ángela Nieto, María Laura Ceci, Albert Blanchart and Jorge GarcíaMarqués for inestimable helpful comments; Paola Bovolenta and Cristina Sánchez-Camacho for their kind gift of the pCAG plasmid; Flora Vaccarino and Giorgio Corte for the generous gift of antibodies against Otp and Foxg1, respectively; Liset Menéndez de la Prida for providing the GAD-GFP transgenic mice; Asta Kastanauskaite and Luz María Suarez for their help with the intracellular injections of Lucifer Yellow and Mark Sefton for editorial assistance. This work was supported by the following grants: BFU2007-60351/BFI from the MICINN, P-SEM-0255-2006 from the OLFACTOSENSE Consortium of the CAM, and FISCAM PI2007-66 from the Castilla-La Mancha Health Research Foundation, to J.A.DC. and the FP6 for the EUTRACC Integrate Project (LSHG-CT-2007-037445), the "Stem Cell Project" of Fondazione Roma and the Italian Association for Cancer Research (AIRC) to A.S. Funding for MP was provided by Fundación CIEN (PI006-08).

\section{Author contributions}

J.A.DC., L.L-M. and F.G-M. planned the experiments. F.G-M. and M.P. performed the experiments and analyzed the data. A.S., L.G.DG., and M. DS. performed and analyzed most of the experiments on Otp mutants. J.A.DC. and F.G-M. discussed the results and wrote the paper.

\section{Competing interests statement}

The authors declare that they have no competing financial interests. 


\section{Supplementary Table 1: Anatomical abbreviations}

\begin{tabular}{|c|}
\hline$A$ \\
\hline ac \\
\hline $\mathrm{AH}$ \\
\hline$B L$ \\
\hline BM \\
\hline BST \\
\hline BST-sc \\
\hline $\mathrm{CC}$ \\
\hline $\mathrm{CC}$ \\
\hline$c p$ \\
\hline $\mathrm{DMH}$ \\
\hline DTJ \\
\hline ec \\
\hline $\mathrm{EC}$ \\
\hline$f$ \\
\hline $\mathrm{FF}$ \\
\hline $\mathrm{fi}$ \\
\hline GP \\
\hline $\mathrm{HC}$ \\
\hline hc \\
\hline HT \\
\hline ic \\
\hline IIIV \\
\hline LG \\
\hline lot \\
\hline LV \\
\hline MeA \\
\hline $\mathrm{mpt}$ \\
\hline nsp \\
\hline OC \\
\hline ot \\
\hline PC \\
\hline PMc \\
\hline POA \\
\hline POc \\
\hline PVH \\
\hline PVHc \\
\hline $\mathrm{Re}$ \\
\hline RT \\
\hline SI \\
\hline SO \\
\hline st \\
\hline Str \\
\hline $\mathrm{T}$ \\
\hline TE \\
\hline Th \\
\hline VMH \\
\hline vzHT \\
\hline vzHTc \\
\hline vzPVH \\
\hline vzTh \\
\hline
\end{tabular}




\section{Figure Legends}

Figure 1 - OTP-expression during embryonic development. Coronal sections. a-c: OTPexpression at E10. a: coronal section at the caudal telencephalic level. b and c: magnification of the boxes in a, showing ventral diencephalic OTP-expression at the dorsal (b) and ventral hypothalamic (c) levels. d-g: OTP-expression at E11. f: magnification of the box in d, showing OTP-ir cells in the mantle region at the boundary between both prosencephalic vesicles. g: magnification of the box in e, showing OTP-expression at the DTJ. $h$-j: OTP-expression at E12. i, $\mathrm{j}$ : microphotographs taken at a similar level to that of the box in $\mathrm{h}$. i: continuous expression from the diencephalon to telencephalon. j: OTP-ir cells in clearly defined telencephalic regions. k-r: OTP-expression at E15. I: magnification of the box in k, showing rostral hypothalamic OTP immunoreactivity. $\mathrm{n}$ : magnification of the box in $\mathrm{m}$, showing OTP-expression at midhypothalamic levels and in the caudal telencephalon. o-r: OTP-expression along BST. $p$ and $r$ are magnifications of the boxes in o and $q$, respectively. s-y: OTP-expression at E18. s: OTPexpression at mid-hypothalamic levels and in the caudal telencephalon. $t-w$ : OTP-expression along BST. $t$ and $v$ are magnifications of the boxes in $u$ and $w$, respectively. $x$ : magnification of the box in $y$, showing amygdaloid OTP immunoreactivity. DAPI labeling in blue. Scale Bars: a,d,f,l, n,o,q,u,w and y: $500 \mu \mathrm{m} ; \mathrm{s:} 250 \mu \mathrm{m}$; e and h: $200 \mu \mathrm{m} ; \mathrm{g}, \mathrm{l}, \mathrm{j}, \mathrm{v}$ and $\mathrm{x}: 100 \mu \mathrm{m} ; \mathrm{b}, \mathrm{c}, \mathrm{p}, \mathrm{r}$ and t: $50 \mu \mathrm{m}$.

Figure 2 - Characterization of the OTP-amygdaloid cells. Coronal sections. a-m: sections obtained from Otp $^{+/}$E18 embryos, showing the distribution of $\beta$-Gal (OTP-cells, red) and Foxg1, Meis2, Zic1 and vGLUT2 (green). a and c: expression of Foxg1 and Meis2, respectively, and $\beta$-Gal. $b$ and $d$ : magnification of the amygdaloid area ( $a$ and $c$ ) showing co-expression of both markers in the MeA. e: Zic1 and $\beta$-Gal expression. $f$ : these factors not co-expressed in the amygdala. g: expression of Zic1 and $\beta$-Gal in the caudal amygdaloid area. h: yellow dots show co-expression in some cells of the BST. i: expression of vGLUT2 and $\beta$-Gal. j: magnification of the amygdaloid area (i). $\mathrm{k}$ : magnification of the box in $\mathrm{j}$ indicating the glutamatergic nature of the $\beta$-Gal-ir cells. I, $\mathrm{m}$ : the same data shown in $\mathrm{j}$ and $\mathrm{k}$ in the caudal amygdaloid area. $\mathrm{n}$-u: morphology of the amygdaloid cells; $n-0$ : E11-electroporated GFPcells and OTP immunoreactivity at P15 in the MeA. p-q: An Otp ${ }^{+-}$mouse in which X-Gal stained cells have been injected with Lucifer Yellow and visualized with DAB. Black arrowhead in $p$ indicates a cell amplified in q. Box in q displays the detail of dendritic spines. r-u: Golgi stained cells in the MeA showing similar morphologies to those displayed by OTP-cells (P30). White arrowhead points to dendritic spines. Scale bars: r,t: $200 \mu \mathrm{m} ; \mathrm{a}, \mathrm{c}, \mathrm{e}, \mathrm{g}$ and $\mathrm{i}$ in a; $\mathrm{p}: 100 \mu \mathrm{m} ; \mathrm{b}, \mathrm{d}, \mathrm{f}, \mathrm{h}, \mathrm{j}$ and $\mathrm{I}$ in b; $n, o, s, u: 50 \mu m ; k$ and $m$ in $m$; q: $25 \mu \mathrm{m}$.

Figure 3 - Cell migration from the hypothalamus to the amygdala. Photographs taken from coronal sections. a: representative cartoons of two coronal sections of E10-E12 brains. Injections at the vzPVH were performed with the aid of an ultrasound system. Green arrow depicts the early migration toward the telencephalon. $b$ : representative cartoons of three coronal sections from E15 brains presenting the distribution of hypothalamic migratory cells (green dots) at mid-developmental stages. c: representative ventral view of an E15 brain showing the three-dimensional location of the traced diencephalic cells. d-I: E15 coronal sections showing the distribution and immunohistochemistry of the vzPVH-derived cells (green). g: example of CFDA injection and hypothalamic distribution of CFDA traced cells. $h$ : 
magnification of the box in $\mathrm{g}$, showing the dorso-lateral migration of cells from the vzPVH. Cells settle in the BST. $d$ : coronal section of CB immunostaining at rostral hypothalamic levels. $i$ and $\mathrm{j}$ : migratory cells surrounding the stria terminalis, magnified from the box in $\mathrm{d}$. Cells neither colocalized with CB (red, i) nor CR (red, j). e: The vzPVH-derived cells settle in the BST-sc, which is immunoreactive for CB. $\mathrm{f}, \mathrm{k}-\mathrm{I}$ : location of traced cells in the amygdala. f: coronal section of CB immunostaining at caudal telencephalic levels. k-l: magnifications from box present in $f$ showing these cells in the MeA and PMc. Cells neither colocalized with CB (red, k) nor CR (red, I). DAPI labeling in blue. Scale bars: g,d and f: $500 \mu \mathrm{m}$; h,k and I: $200 \mu \mathrm{m}$; i-e: $50 \mu \mathrm{m}$.

Figure 4 - Cellular migration from the hypothalamus to the amygdala. a: representative cartoons of two coronal sections from E10-E12 brains. Injections at the VZPVH were performed with the aid of an ultrasound system. Green arrow traces the early migration toward the telencephalon. b: representative cartoons of two coronal sections from E18 brains showing the distribution of the hypothalamic migratory cells (green dots) at later stages of development. co: E18 coronal sections showing the final distribution and immunohistochemistry of the VzPVHderived cells (green). c: rostral hypothalamic section. d: magnification of the box in c showing the VzPVh injection, and the radial distribution of cells in the hypothalamus and the nearby BST. e: example of tiny BDA injection (arrow; green cells) and the location of the traced cells in the PVH and BST. $f$ and e: VzPVH-derived cells at the BST neither express Tbr1 (f) nor CB (e). $\mathrm{h}$-i: higher view of diencephalic migratory cells at the BST immunostained for $C B(h)$ and $C R(j)$. j-o: telencephalic location of hypothalamic migratory cells in the amygdala. Cells settle in the initial path of the stria terminalis $(I, m), \operatorname{MeA}(j, k, m$ and $n), P M c(j, I, m)$ and sparsely in the POc (o). Several markers of well-known distributions were used to describe the final distribution of the vzPVH-derived cells, such as CR (j), CB ( $k, l)$ and Tbr1 (m-o). DAPI labeling in blue. Scale bars: c: $500 \mu \mathrm{m} ; \mathrm{d}, \mathrm{f}, \mathrm{g}$ and m-o: $250 \mu \mathrm{m} ; \mathrm{e}, \mathrm{i}$ and j: $100 \mu \mathrm{m} ; \mathrm{h}$ and $\mathrm{k}: 50 \mu \mathrm{m}$; l: $25 \mu \mathrm{m}$.

Figure 5 - Diencephalic migratory cells express OTP (red). Coronal sections. a: rostral hypothalamic section at the level where microphotographs b-f were taken. g: medial hypothalamic section at the level where microphotographs $h-i$ were taken. $j$ : caudal telencephalic section immunostained for OTP at the level where microphotographs $\mathrm{k}-\mathrm{I}$ were taken. The vzPVH-derived cells (green) express OTP at all levels of their final distribution: in the hypothalamus (b-c), BST (d-f), BST-sc (g-i) and in the vomeronasal amygdala (j-I). DAPI labeling in blue. Scale bars: a,g and j: $500 \mu \mathrm{m} ; \mathrm{c}-\mathrm{e}, \mathrm{h}, \mathrm{i}, \mathrm{k}$ and I: $200 \mu \mathrm{m}$; b: $50 \mu \mathrm{m} ; \mathrm{f:} 25 \mu \mathrm{m}$.

Figure 6 - OTP-silenced cells failed to colonize the telencephalon. Embryos were transfected int utero by electroporation of shRNA molecules at E10. For silencing experiments shRNA-Otp was electroporated and a control-vector target RNAi. In both experiments, cells were labeled by transfection of GFP-expression plasmids at a lower concentration than shRNA (1:3) to ensure that GFP-labeled cells also carry shRNA plasmids. Final location of transfected cells was studied at E18. a-f: cellular distribution of GFP-electroporated cells in control experiments. g-l: cellular distribution in silencing experiments. a-g: coronal section in which b-h photographs were taken. b-h: distribution of transfected cells at the rostral hypothalamic level. OTP silencing led to a general disorganization in the distribution of these cells. The proportion of GFP-labeled cells increased at the hypothalamic level in silenced animals (c-i,p), whereas it decreased at the BST (d-j,p) and at amygdaloid levels (e,k, and f,l). m-o: percentage of GFPtraced cells in the hypothalamic (m), BST-sc ( $n$ ) and amygdaloid (o) area where OTP is 
expressed in control (black) and silenced embryos (grey). The percentage of silenced cells represents the proportion of GFP-traced cells that lack OTP-expression normalized to the control data. p: proportion of GFP-cells that colonizes the OTP-ir areas in control (blue) and silenced (red) embryos. Bars represent the mean of 4 independent animals and the bars show the standard error. DAPI labeling in blue. Data are presented as mean \pm s.e.m. Scale bars: a and g: $1 \mathrm{~mm} ; \mathrm{b}$ and h: $250 \mu \mathrm{m}$; c-f and i-l: $50 \mu \mathrm{m}$.

Figure 7 - Failure of OTP-expressing cells to migrate in Otp ${ }^{-1}$ embryos. a-l: Immunohistochemistry against $\beta$-Gal in $\operatorname{Otp}^{+/-}(\mathrm{a}-\mathrm{c}, \mathrm{g}-\mathrm{i})$ and $\mathrm{Otp}^{-/-}(\mathrm{d}-\mathrm{f}, \mathrm{j}-\mathrm{I})$ embryos at $\mathrm{E} 15$ and E18. In Otp $^{+/-}$embryos, OTP-cells are detected in the BST, MeA, PMc and SO, while almost no amygdaloid staining is observed in Otp ${ }^{-/}$embryos. , The dense accumulation of OTP-cells in the dorsal part of the $\mathrm{PVH}$ of $\mathrm{Otp}^{-/}$embryos is absent, while persists in its ventral part and in the VMH, cPVH and POA. m-aj: Coexpression of OTP and SIM1 in Otp ${ }^{+-}$(m-p,u-x,ac-af) and Otp ${ }^{-/-}$ (q-t,y-ab,ag-aj) embryos at E13, E15 and E18. Images of darkfield correspond to in situ hybridizations with the LacZ and Sim1 probes, while brightfield images correspond to $\beta$-Gal immunohistochemistry. White arrowheads in the MeA indicate the differences of OTP-cells between Otp $^{+/}$and Otp ${ }^{-/}$embryos. Red arrows point to OTP/Sim1 cells the BST and PVH showing the differences between $O t p^{+/}$and $O t p^{-/}$embryos. Green arrowheads indicate Sim1 cells variation in the BM between Otp ${ }^{+-}$and Otp ${ }^{-/}$embryos. Scale bars: u-ab in u: $500 \mu \mathrm{m}$; a-f in a: $300 \mu \mathrm{m}$; m-t in m: $250 \mu \mathrm{m}$; g-l in g, ac-aj in ac: $200 \mu \mathrm{m}$. Coronal sections.

Figure 8 - Altered patterning of the amygdala in Otp ${ }^{-1-}$ embryos. Expression of $\beta$-Gal (red) in $\operatorname{Otp}^{+-}(a, c, e, g, l, k, m, o, q, s, u)$ and $\operatorname{Otp}^{-/-}(b, d, f, h, j, l, n, p, r, t, v)$ embryos at E18. Coronal sections of left hemispheres, taken from three rostro-caudal levels (anterior, medial and posterior). a-f: Tbr1 expression pattern is similar in Otp ${ }^{+/}$and Otp ${ }^{-/-}$embryos except for the TE. g-l: Lhx5 colocalizes with $\beta$-Gal. Therefore, in the amygdala of $O t p^{-/-}$embryos no staining is detected (asterisks). m-r: Lhx6 expression pattern at the BST is restored to control. s-x: Lhx1 expression pattern is altered in the TE, while is not detected in the amygdala. $y$-ad: representative cartoons of the altered amygdaloid patterning at rostral $(y, z)$, medial (aa,ab) and caudal levels (ac,ad) of the migratory pathway in Otp ${ }^{+/}$and $\mathrm{Otp}^{-/-}$embryos. Scale bar: $200 \mu \mathrm{m}$.

\section{Cover picture legend}

Crossing brain boundaries. Diencephalic OTP-expressing cells cross through the ditelencephalic junction at early stages of development (E14), as seen by immunohistochemistry in red color. The stria terminalis appears in green color traced with GFP. Internal capsule has been pseudocolored in yellow; diencephalic cells in blue and some telencephalic cells in purple. 


\section{Supplementary Figure Legends}

Supplementary Figure 1 - Time frame of the generation of OTP-expressing neurons and its coexpression with other phenotypic markers. Coronal sections. a, b: BrdU injection at E13 visualized at E18. OTP-ir cells (red) are generated prior to E13 because no OTP-ir cells colocalized with BrdU (green) at the hypothalamic ( $a$ and inset) or amygdaloid levels (b and inset). c: magnification of the box in the inset showing that OTP-ir cells in the amygdaloid area (red) do not express TH (green) and thus, they are not dopaminergic neurons. d-g: OTP-ir cells are not GABAergic. d: magnification of the box in the inset shows the GFP expression in GAD67-GFP E13 mouse embryo. OTP-ir cells (red) do not express GAD67. e: amplified view of amygdaloid OTP expressing cells. DAPI labeling in blue. $\mathrm{f}-\mathrm{i}$ : in situ hybridization with the probes for OT, AVP, TRH and GHRH to show they are not expressed in the amygdaloid area. $\mathrm{j}-\mathrm{l}$ : sections from $\mathrm{Otp}^{+/-}$mice immunostained for SS, CRH or ChAT (green), and $\beta-$ Gal (red) to show that OTP-cells do not express any of these markers. Boxes in $\mathrm{j}-\mathrm{I}$ are magnifications of the MeA to show that these markers are not co-expressed. Scale bars: a-c: $100 \mu \mathrm{m} ; d$ and f-i in f: 200 $\mu \mathrm{m}$; e: $50 \mu \mathrm{m}$; j-l in j: $100 \mu \mathrm{m}$.

Supplementary Figure 2 - Co-expression of OTP with some phenotypic markers in the BST and in the anterior hypothalamus. a,b,e,f,i,j,m,n: expression in the BST of $\beta$-Gal with Foxg1, Zic1 and Meis2, in Otp ${ }^{+/}$and $\mathrm{Otp}^{-/}$mice. a-e,i,m: Foxg1, Meis2 and Zic1 co-express in the BST with OTP in Otp ${ }^{+/-}$mouse. b,f,j,n: Foxg1, Meis2 and Zic1 expression pattern is disturbed in the Otpknockout but it remains the colocalization with OTP. c,d,g,h,k,l,o,p: expression in the anterior hypothalamus of $\beta$-Gal with Foxg1, Zic1 and Meis2, in Otp ${ }^{+/}$and Otp ${ }^{-/}$mice. c,g,k,o: Foxg1, Meis2 and Zic1 co-express in the POA with OTP in Otp ${ }^{+/-}$mouse, but not colocalize in the AH (f). $\mathrm{d}, \mathrm{h}, \mathrm{l}, \mathrm{p}$ : Foxg1, Meis2 and Zic1 expression pattern is disturbed in the Otp-knockout: the $\beta$-Gal pattern is ventralized (the colocalization remains). Scale bars: $a, b, c$ and $d$ in a: $500 \mu \mathrm{m}$; e-p in e: $100 \mu \mathrm{m}$.

Supplementary Figure 3 - Spatial relationship between diencephalic cells and amygdaloid axons. Coronal sections. a: Embryos were injected in utero with CFDA in the third ventricle at E12. b: The stria terminalis was traced by introducing a small Dil crystal into the amygdala on fixed E18 tissue. c: Dil labeling at the stria terminalis and of some axons at the olfactory cortex. $\mathrm{d}$ : magnification of the box in c. CFDA (green) labeled cells were generated at E12 and migrated to settle close to the stria terminalis. e: diencephalic migratory cells (green) located at the BST-sc, spatially related to stria terminalis. f: OTP immunohistochemistry at E18 on Dil labeled tissue showing the spatial relationship between OTP-ir cells of the BST-sC and the stria terminalis. OTP-ir cells remain in the equivalent position to that found after CFDA intrauterine injections. DAPI labeling in blue. Scale bars: $a$ and b: $1 \mathrm{~mm}$; : $500 \mu \mathrm{m}$; d,e and f: $100 \mu \mathrm{m}$.

Supplementary Figure 4 - Early migration of neuroblasts from the vzPVH. Embryos were injected with CFDA at E10 or E11 and subsequently cultured in toto. a: cartoon representing two coronal slices after embryo culture showing the tangential migration from the vzPVH. Cells from the vzPVH migrate dorso-laterally and slightly rostral to colonize the telencephalon. $b$ : cartoon representation of the whole brain in a lateral view, where the migratory path is depicted by a red arrow. c: latero-ventral view of a whole brain traced with CFDA. The green labeling shows the hypothalamic level of the injection. The rest of the pictures are taken from 
coronal sections. $d$ and e: sections of the traced brains showing CFDA at the VzPVH. $f$ : magnification of the box in e, showing OTP-expression and the injection the hypothalamic level. g: magnification of the box in the inset. Labeled cells migrated dorsally from the injection site. $h$ : coronal section slightly rostral to the injection of CFDA. i: magnification of the box in $h$, showing the first telencephalic OTP-expressing cells. $\mathrm{j}$ : magnification of the box in $\mathrm{i}$, that shows CFDA traced cells expressing OTP (arrowheads). k: magnification of the box in the inset showing telencephalic OTP-ir cells at the subpallial mantle zone. I: magnification of the box in $\mathrm{k}$ showing CFDA traced cells expressing OTP (arrowheads). m: microphotograph at the level of I showing that diencephalic migratory cells do not express calbindin. DAPI labeling in blue. Scale bars: c: $1 \mathrm{~mm}$; e,h and inset in k: $500 \mu \mathrm{m}$; d,i and k: $250 \mu \mathrm{m}$; f and g: $100 \mu \mathrm{m} ; \mathrm{j}, \mathrm{l}$ and m: $50 \mu \mathrm{m}$.

Supplementary Figure 5 - Early cellular migration from the ventral thalamic ventricular zone. a: representative cartoons of a coronal section from an E10-E12 brain. Injections at the vzTh were performed with the aid of an ultrasound system and the red arrow traces the early radial migration towards the lateral thalamus. Dotted line represents the diencephalic sulcus that separates the thalamic and hypothalamic primordia. b: representative cartoons of three coronal sections from an E15 brain showing the distribution of the migratory thalamic cells (red dots) at mid- and late stages of development. c-i: final distribution of thalamic traced cells at E15 (green, c-f) and E18 (red, g-i). d and f: example of a CFDA injection at the vzTh, magnified from box in $c$ and $e$, respectively. Cells that migrate radially settle in the thalamic nuclei Reuniens and lateral geniculate. Cells do not cross the diencephalic sulcus as witnessed by $\mathrm{CB}$ immunohistochemistry (f). $\mathrm{h}$ and $\mathrm{i}$ : magnifications of the box in g. BDA injections (arrows) traced radial migratory cells that did not cross the diencephalic sulcus (dotted line), or express CB (green, h) or OTP (green, i). DAPI labeling in blue. Scale bars: c,e and g: $500 \mu \mathrm{m}$; and h: $200 \mu \mathrm{m}$; f and i: $100 \mu \mathrm{m}$.

Supplementary Figure 6 - Early cell migration from the caudal hypothalamic ventricular zone. a: representative cartoons of a coronal section from an E10-E12 brain. Injections at the VzHTC were performed with the aid of an ultrasound system and the blue arrow traces the early radial migration towards the lateral hypothalamus. Migratory cells never colonize the telencephalon. b: representative cartoons of two coronal sections from an E15 brain showing the distribution of the migratory hypothalamic cells (blue dots) at mid- and late stages of development. Dotted line represents the diencephalic sulcus that separates the thalamic and hypothalamic primordia. c-f: final distribution of thalamic traced cells at E18 (green, c-f). d: higher magnification view of the box in c, showing the radial distribution of the vzHTc-derived cells. There are no cells in the amygdala. e and $f$ : magnifications of the box in $d$. Radial migratory cells colonize the lateral hypothalamic nuclei and they neither express $C B$ (e) nor OTP (f). DAPI labeling in blue. Scale bars: c: $500 \mu \mathrm{m}$; d: $250 \mu \mathrm{m}$; e and f: $100 \mu \mathrm{m}$.

Supplementary Figure 7 - Cellular death and proliferation of silenced cells. a-c: TUNEL assay in intrauterine silenced embryos in the short (E11-13; $a$ and C) and long term (E10-E18; b,d and e). Electroporated hemispheres (right, $\mathrm{GFP}^{+}$in a and b) did not show variation in TUNEL labeling ( $c$ and $d$ ) in comparison to contralateral non-silenced hemispheres (left). e: Positive control of TUNEL staining. f: pH3 immunohistochemistry (red) on silenced embryos. Early (E11) OTP silencing did not modify the diencephalic proliferation at E13. g: the number of mitotic cells in the diencephalic nuclei was similar in silenced (red) and non-silenced (green) 
hemispheres. DAPI labeling in blue. Data are presented as mean \pm s.e.m. Scale bars: $a, b$ and $f$ : $250 \mu \mathrm{m}$; e: $100 \mu \mathrm{m}$.

Supplementary Figure 8 - Coronal sections from E18 Otp ${ }^{+/-}(a-d)$ and Otp ${ }^{-/-}\left(a^{\prime}-d^{\prime}\right)$ Nissl stained embryos showing the differences in cell densities (black arrowheads) in MeA, BST and PMc. Scale bars: a,c,e,g in a: $200 \mu \mathrm{m} ; \mathrm{b}, \mathrm{d}, \mathrm{f}, \mathrm{h}$ in b: $100 \mu \mathrm{m}$.

Supplementary Figure 9 - The stria terminalis is not altered in Otp ${ }^{-1-}$ knockout mice. Coronal sections showing the stria terminalis traced with Dil crystals from the amygdaloid area in E18 $\operatorname{Otp}^{+/}(\mathrm{a}-\mathrm{c})$ and $\operatorname{Otp}^{-/-}\left(\mathrm{a}^{\prime}-\mathrm{c}^{\prime}\right)$ mouse embryos. Scale bars: $\mathrm{a}$ and $\mathrm{d}$ in a, c and e in c: $250 \mu \mathrm{m} ; \mathrm{b}$ and f: $100 \mu \mathrm{m}$.

Supplementary Figure 10 - Altered patterning of the amygdala in Otp ${ }^{-/-}$embryos. Expression of $\beta$-Gal (red) in Otp+/- $(a, c, e, g, l, k, m, o, q)$ and Otp-/- $(b, d, f, h, j, l, n, p, r)$ embryos at E15. Coronal sections of left hemispheres, taken from three rostro-caudal levels (anterior, medial and posterior). a-f: Tbr1 expression is altered in the TE, BST (arrowheads) and in a ventral extension of the BM (arrows). g-I: Lhx5 colocalizes with $\beta$-Gal. Therefore, in the amygdala of $\mathrm{Otp}^{-/-}$embryos no staining is detected (asterisks). $\mathrm{m}$-r: Lhx6 expression pattern is disorganized in the BST. Scale bar: $500 \mu \mathrm{m}$.

Supplementary Figure 11 - Visualization of an early mouse embryo through the ultrasound system VEVO 770. a: visualization of the areas of interest including the uterine muscle, placenta, yolk sac, lateral and third ventricles and diencephalic sulcus (dotted line). The white circle indicates the vzPVH. The needle tip presents an ultrasound reflection and it is therefore actually smaller than it appears. b: visualization of the injection. The bright area to the left of the vzPVH shows the micro-needle tip at the moment of tracer injection. Red line represents the injection trajectory.

Supplementary Movie 1 - Sample video of ecographic visualization and tracer injection into VzPVH at E12. 


\section{Methods}

\section{Animals}

Embryos (113) were obtained from wild type C57 and transgenic GAD67-GFP CD1 pregnant mice (22), raised in our in-house colony at the Cajal Institute. The day of detection of the vaginal plug was considered as embryonic day 0 (E0). The Otp-knockout mouse used was generated and housed in Naples (Italy). The Otp ${ }^{+/-}$(used as controls) and Otp ${ }^{-/-}$embryos were genotyped as previously reported ${ }^{27}$ and they were analyzed by immunohistochemistry and in situ hybridization: a total of $18 \mathrm{Otp}^{+/-}$and $19 \mathrm{Otp}^{-/-}$embryos at the stages of E13, E15 and E18 were used here. All procedures for animal handling and sacrifice used in this study were in accordance with the European Commission guidelines (86/609/CEE) and they were approved by the animal care and use committee of the Cajal Institute.

Pregnant dams were anesthetized with Equithesin ( $3 \mathrm{ml} / \mathrm{kg}$ body weight) before surgery to remove the embryos by cesarean section at different developmental stages (E10, E11, E12, E13, E15 and E18), and then they were sacrificed by cervical dislocation. The embryos were used as follows: 23 were used for immunohistochemistry studies (20 from C57 and 3 from GAD67-GFP CD1); 10 were injected exo utero with tracers and cultured in toto (2 different experiments with 5 embryos each); 40 were injected with tracers in utero (8 different experiments with 5 embryos each); 40 were electroporated in utero (4 different experiments with 10 embryos each).

\section{Whole embryo culture}

The experimental procedures for whole embryo culture using an incubator and a roller bottle system were largely based on the protocol described in detail elsewhere ${ }^{35,45}$. Briefly, mouse embryos (E10/E11) were removed from the uterus and dissected out in a Petri dish containing Hank's balanced solution at $37^{\circ} \mathrm{C}$ under sterile conditions. While maintaining the integrity of the vitelline arteries and veins, the yolk sac was partially broken to expose the embryo. Tracers were injected with the aid of a dissecting microscope (Nikon SMZ1500; Nikon Corporation, Tokyo) and a pressure device (Picospritzer; General Valve, Fairfield, CT). Subsequently, the injected embryo was transferred to a glass bottle containing $4 \mathrm{ml}$ of culture medium, which was placed in an incubator for 1 day at $35^{\circ} \mathrm{C}$ with continuous gassing $\left(95 \% \mathrm{O}_{2}\right.$, $5 \% \mathrm{CO}_{2}$ ). The culture medium used was heat-inactivated rat serum obtained by centrifugation of blood from the donor animal (three times at $9000 \mathrm{rpm}$ for 5 minutes each). This serum was filtered with Filtropur S 0.45 (Sarstedt, Nümbrecht) and supplemented with $1 \mathrm{mg} / \mathrm{ml}$ glucose and antibiotic (penicillin-streptomycin, $100 \mathrm{IU} / \mathrm{ml}$; Gibco, Grand Island, NY).

\section{Birthdating studies}

Timed-pregnant mice (E13) were injected with a single intraperitoneal injection (50 mg/Kg body weight) of 5-Bromo-2'-deoxyuridine-5'-monophosphate solution dissolved in sterile 0.1 $\mathrm{M}$ Tris- $\mathrm{HCl}$ buffer (BrdU; Boehringer Mannhein, Indianapolis, IN), five days before sacrifice. 
Embryos were transcardially perfused with $4 \%$ paraformaldehyde (PFA) and postfixed overnight. The brains were cut into $10 \mu \mathrm{m}$ thick sections using a cryostat (Leica CM 1900; Leica Inc, Germany) and the sections were first incubated in $2 \mathrm{~N} \mathrm{HCl}$ for $60 \mathrm{~min}$, and then thrice (10 $\mathrm{min}$ ) in $0.1 \mathrm{M}$ borate buffer ( $\mathrm{pH} \mathrm{8.5)}$ to neutralize the residual acid. Finally, the sections were stained with an anti-BrdU antibody $(0.25 \mu \mathrm{g} / \mathrm{ml}$; Roche applied science; Mannheim, Germany) that was visualized with Alexa-conjugated secondary antibodies.

\section{Intrauterine experiments}

Embryos were injected to specifically label newly generated cells or to fill up the third ventricle using an ultrasound guided injection system, VeVo $770^{\circledR}$ (VisualSonics Inc. Toronto, Canada; Supplementary Movie 1 and Supplementary Figure 11). Briefly, E10-E12 pregnant mice were anesthetized with isoflurane (Isova vet, ref. 240055; Centauro, Barcelona, Spain), the uterine horns were exposed out of the abdominal wall and covered with pre-warmed ultrasound gel (Parker Laboratories, Inc. NJ USA). Each embryo was injected with a volume of $100 \mathrm{nl}$ of the dye into the tissue (Supplementary Movie 1), or 1-2 $\mu$ l of the dye or recombinant plasmid solution into the third ventricle; then the embryos were electroporated. After surgery, the antibiotic enrofloxacin (5 mg/Kg; Baytril; Bayer, Leverkusen, Germany) and the antiinflammatory ketorolac (300 $\mathrm{\mu g} / \mathrm{Kg}$; Droal; VITA Laboratories, Barcelona, Spain) was administered to the pregnant mice and the injected embryos were allowed to survive until E15 or E18.

\section{Tracers and injections}

Three different tracers were employed in this study: 1) Crystals of 1,1'-dioctadecyl$3,3,3^{\prime}, 3^{\prime}$-tetra-methyl-indocarbocyanine perchlorate (Dil, Molecular Probes, Eugene, OR, USA); 2) $5 \%$ aqueous solution of biotinylated dextran amine (BDA; 3,000 molecular weight; Molecular Probes); 3) $10 \mathrm{mM}$ solution of carboxy-fluorescein diacetate succinimidyl ester (CFDA SE) in dimethyl sulfoxide (557 molecular weight; Molecular Probes). Dil was employed on fixed tissue, introducing a small crystal into the amygdala to label the stria terminalis. CFDA and BDA were injected into several diencephalic germinative zones.

\section{Electroporations and shRNA silencing}

Hypothalamic ventricular zone cells were transfected in utero by means of a BTX Electroporator ECM 830 (BTX; Massachusetts, USA). Electroporation was accomplished by 5 pulses $(50 \mathrm{~ms}$ ) discharging a $500 \mu \mathrm{F}$ capacitor charged to $25 \mathrm{~V}$ with a sequencing power supply. The voltage pulse was discharged across a pair of platinum round plates ( $5 \mathrm{~mm}$ diameter). Two different solutions of DNA plasmids were electroporated. The negative control experiment was performed by co-transfecting a mixture of pCAGGS/eGFP $(1 \mu \mathrm{g} / \mu \mathrm{l}$; kindly gift of Paola Bovolenta, Cajal Institute) and a Control Non-Target shRNA SIGMA ${ }^{\circ}$ (SHC002; $\left.3 \mu \mathrm{g} / \mu \mathrm{l}\right)$. The silencing experiment was performed by co-transfecting a mixture of pCAGGS/eGFP $(1 \mu \mathrm{g} / \mu \mathrm{l})$ 
and the five commercial plasmids designed to silence the Otp translation (Mission shRNA-Otp SIGMA ; SHCLNG-NM_011021; $3 \mu \mathrm{g} / \mu \mathrm{l})$.

\section{Immunohistochemistry}

Single and dual immunohistochemistry reactions were performed in this study as described before ${ }^{45}$ using the following primary antibodies: Mouse-anti-Reelin (Chemicon; Temecula, CA; MAB5364, Clone G10; 1:1000); Rabbit-anti-Calbindin-D28K (CB; Swant; Bellinzona, Switzerland; CB38; 1:10000); Rabbit-anti-Calretinin antiserum (CR; Swant; 7699/4; 1:2000); Mouse-anti- $\beta$-Tubulin class III (TuJ1; Chemicon; MAB1637; 1:1000); Rabbit-antiPhospho Histone 3 (p-H3; Chemicon; 06-570; 1:1000) Mouse-anti-Tyrosine hydroxylase (TH; Chemicon; MAB318; 1:1000); Rabbit-anti-Tbr1 (Chemicon; AB9616; 1:1000); Rat-anti-GFP (Nacalai Tesque; Kyoto, Japan; 04404-84; 1:2000); Rabbit-anti-OTP (gift from Flora Vaccarino, Yale University; $1: 2000$ ); Rabbit-anti- $\beta$-Galactosidase ( $\beta$-Gal; Nordic Immunology; Tilburg, The Netherlands; Neo-56 Pab; 1:500); Chicken-anti- $\beta$-Galactosidase ( $\beta$-Gal; Abcam; Cambridge, UK; AB3661; 1:400); Rabbit-anti-Somatostatin (SS; Zymed; San Francisco, CA ; 18-0078; 1:100); Rabbit-anti-vGLUT2 (Synaptic Systems; Goettingen, Germany; 135403; 1:75); Rabbit-anti-Zic1 (Novus Biologicals; Littleton, CO; NB600-488; 1:600); Rabbit-anti-Foxg1 (kindly provided by G. Corte; 1:1000); Rabbit-anti-Lucifer Yellow (LY, Instituto Cajal; Madrid, Spain; 1:100000); Rabbitanti-Corticotropin Releasing Hormone (CRH; Abcam; AB8901-100; 1:75); Goat-anti-Choline Acetyltransferase (ChAT; Millipore; Billerica, MA; AB144-P; 1:75); Mouse-anti-Meis2 (Abnova; Paseo Del Prado Walnut, CA; H00004212-H01; 1:200); Rabbit-anti-Lhx1 (Abcam; AB14554; 1:300); Rabbit-anti-Lhx6 (Abcam; AB22885; 1:200); Goat-anti-Lhx5 (Santa Cruz Biotechnology; Heidelberg, Germany; sc-19347; 1:40); Mouse anti-BrdU (G3G4 IgG1, kappa light chain isotype, Developmental Studies Hybridoma Bank; University of lowa; 1:2000). To visualize the incorporation of $\mathrm{BrdU}$, treatment with $\mathrm{HCl} 2 \mathrm{~N}$ was necessary for 30 minutes to make the epitope accessible to the primary antibody.

The secondary antibodies used in this study were: Alexa 568 Goat-Anti-Rabbit IgG (Molecular Probes; A11011; 1:2000); Alexa 568 Anti-Mouse IgG (Molecular Probes; A11004; 1:2000); Alexa 488 Anti-Rat (Molecular Probes; A11034; 1:2000); Alexa 568 Streptavidin (Molecular Probes; S11225; 1:2000); Alexa 488 Streptavidin (Molecular Probes; S11223; 1:2000); Biotinylated Donkey Anti-Rabbit (Amersham Pharmacia Biotech; Little Chalfont, UK; RPN1004; 1:200). The antibody against LY was recognized with a biotinylated secondary antibody and visualized using a biotin-horseradish peroxidase complex (Amersham Pharmacia Biotech; RPN1051; 1:200) and 3,3'-diaminobenzidine (DAB; Sigma Chemical; St. Louis, MO; D8001) as the chromogen. Immunohistochemistry with the antibody against $\beta$-Gal was visualized with the Mach4 Universal HRP-Polymer Kit (Biocare Medical; Pike Lane Concord, CA; M4U534L) using the 3-Amino-9-Ethylcarbazole chromogen (Sigma Chemical; A5754).

For all antibodies a series of control sections were stained where the primary antibody was omitted and no specific staining was seen. The sections were mounted on gelatinized slides and counterstained with $0.002 \%$ solution of bisbenzimide in PBS (Hoechst 33258; Sigma; St. Louis, MO).

Cell Death was detected by TUNEL labeling using the In Situ Cell Death Detection Kit, AP (Roche applied science, 11684809 910). Negative and positive controls were assessed for each tissue sample. 


\section{In situ hybridization}

In situ hybridization was performed as described previously ${ }^{24,25,27}$. The probes for Sim1, LacZ, oxytocin (OT), arginine vasopressin (AVP), thyrotropin-releasing hormone (TRH) and growth-hormone-releasing hormone $(\mathrm{GHRH})^{27}$ were RT-PCR fragments of $348 \mathrm{bp}, 800 \mathrm{bp}, 370$ bp, 425 bp, $447 \mathrm{bp}$ and $354 \mathrm{bp}$, respectively.

\section{Equipment and settings}

Injected embryos were fixed in 4\% PFA and examined under a fluorescence-dissecting microscope (Leica MZFL-III). The brains were then embedded in agar, and $50 \mu \mathrm{m}$ vibratome sections were obtained in the coronal plane. Fluorescent sections were mounted with a mixture of glycerol-phosphate buffer (PB, 1:1) and studied under a fluorescent microscope (Nikon, Eclipse E600) equipped with a digital camera (Nikon DMX 1200F) and the appropriate filter cubes: rhodamine $(569-610 \mathrm{~nm})$ or fluorescein $(450-490 \mathrm{~nm})$ to visualize Dil/Alexa 568 and CFDA/GFP/Alexa 488, respectively. Bisbenzimide labeling was studied under ultraviolet illumination. Selected areas with double-labeled cells were also studied and photographed using a Leica TCS 4D confocal microscope. BDA and CFDA-injected embryos were initially fixed in 4\% PFA, and their brains were postfixed in fresh 4\% PFA supplemented with $30 \%$ sucrose in $0.1 \mathrm{M} \mathrm{PB}$ at 4 으 until the tissue sank in the medium. Coronal frozen cryostat sections $(20 \mu \mathrm{m})$ were obtained (Frigocut N; Leica Inc.; Germany) and mounted on Tespa-coated glass slides. In order to perform dual immunohistochemistry, sections from BDA-injected embryos were incubated with Alexa 488/568 streptavidin.

\section{Cell quantification}

For the Otp-inhibition assay, 6 brain sections from the rostral hypothalamus to the caudal amygdala were studied for each embryo (at least 3 embryos per experiment) using confocal picture stacks and ImageJ software (http://rsb.info.nih.gov/ij/index.html; NIH; USA). Only embryos electroporated at the VzPVH were selected, although a secondary electroporation was usually carried out (normally at the cerebral cortex or thalamus). All the GFP-expressing cells in the OTP-expression area were counted, distinguishing three distinct migratory domains: hypothalamus (electroporated region and PVH), BST/BST-sc and amygdala (MeA and PMc). To compare the migration between controls versus silenced embryos, we analyzed the proportion of GFP-expressing diencephalic derived cells, since the number of GFP-cells showed a three-fold variation between embryos. The percentage of GFP-cells in each region was compared with the Student $t$ test. The total number of OTP-cells in each region was very similar between embryos, supporting the quantification of GFP-expressing cells.

To test the possible alterations to proliferation in silenced embryos, we compared the diencephalic hemispheres electroporated with the controls (contralateral hemisphere that had 
suffered the electric pulse but do not express the plasmids). We counted a total of 16 sections ( 32 hemispheres) from 4 silenced embryos and the results were analyzed with the Student $t$ test.

\section{Morphological analysis}

In order to study the morphology and disposition of the OTP-expressing cells in the telencephalon, we used different approaches: 1) In utero injection of a GFP-plasmid (see above) into the third ventricle of E11 embryos that was electroporated to permanently label zVPVH cells. The animals were sacrificed at P15. Coronal sections with GFP-labeled cells in the amygdala were immunolabeled with the OTP antibody. 2) Intracellular injections of Lucifer Yellow (LY) into identified OTP-positive cells of the MeA. A couple of Otp ${ }^{+/-}$brains were fixed by immersion in $0.2 \%$ glutaraldehyde for $30-45$ minutes, washed in PB with $0.01 \% \mathrm{Na}$ Deoxycolate and $0.02 \%$ IGEPAL, stained with X-Gal and post-fixed and stored for 2 days in $4 \%$ PFA. In coronal vibratome sections (150 $\mu \mathrm{m}$ thickness), single amygdaloid X-Gal stained neurons in MeA were iontophoretically filled with LY using a 20-30 nA continuous current. Finally, the sections were processed by immunohistochemistry and visualized using DAB as the chromogen. 3) Golgi Method. Two adult mice (P30) were fixed by transcardial perfusion with 4\% PFA in $0.1 \mathrm{M}$ phosphate buffer [pH 7.2] and their brains were removed, blocked and processed for the Golgi method as described before ${ }^{46}$. 4) Nissl Method. One Otp ${ }^{-1}$ and one control $\mathrm{Otp}^{+/-}$E18 embryo was fixed by immersion in 4\% PFA for 12-16 hours, dehydrated, wax embedded and sectioned at $8 \mu \mathrm{m}$ thickness in the coronal plane. Sections were stained with $0.5 \%$ cresyl violet in distilled water, dehydrated, clear in xylene and mounted with DPX. The counterstained sections allowed us to study and compare the shape and size of the nuclei that contain OTP-cells. 


\section{References}

1. Swanson, L.W. \& Petrovich, G.D. What is the amygdala? Trends Neurosci 21, 323-331 (1998).

2. Alheid, G.F. \& Heimer, L. New perspectives in basal forebrain organization of special relevance for neuropsychiatric disorders: the striatopallidal, amygdaloid, and corticopetal components of substantia innominata. Neuroscience 27, 1-39 (1988).

3. Cassell, M.D., Freedman, L.J. \& Shi, C. The intrinsic organization of the central extended amygdala. Ann N Y Acad Sci 877, 217-241 (1999).

4. Shammah-Lagnado, S.J., et al. Supracapsular bed nucleus of the stria terminalis contains central and medial extended amygdala elements: evidence from anterograde and retrograde tracing experiments in the rat. J Comp Neurol 422, 533-555 (2000).

5. Holmgren, N. Points of view concerning forebrain morphology in higher vertebrates. Acta Zool Stockh 6,413-447 (1925).

6. Swanson, L.W. Cerebral hemisphere regulation of motivated behavior. Brain Res 886, 113-164 (2000).

7. Puelles, L. Brain segmentation and forebrain development in amniotes. Brain Res Bull 55, 695-710 (2001).

8. Martínez-García, F., Martínez-Marcos, A. \& Lanuza, E. The pallial amygdala of amniote vertebrates: evolution of the concept, evolution of the structure. Brain Res Bull 57, 463-469 (2002).

9. Medina, L., Brox, A., Legaz, I., García-López, M. \& Puelles, L. Expression patterns of developmental regulatory genes show comparable divisions in the telencephalon of Xenopus and mouse: insights into the evolution of the forebrain. Brain Res Bull 66, 297-302 (2005).

10. Tole, S., Remedios, R., Saha, B. \& Stoykova, A. Selective requirement of Pax6, but not $E m \times 2$, in the specification and development of several nuclei of the amygdaloid complex. J Neurosci 25, 2753-2760 (2005).

11. Puelles, L., et al. Pallial and subpallial derivatives in the embryonic chick and mouse telencephalon, traced by the expression of the genes Dlx-2, Emx-1, Nkx-2.1, Pax-6, and Tbr-1. J Comp Neurol 424, 409-438 (2000).

12. Medina, L., et al. Expression of Dbx1, Neurogenin 2, Semaphorin 5A, Cadherin 8, and Emx1 distinguish ventral and lateral pallial histogenetic divisions in the developing mouse claustroamygdaloid complex. J Comp Neurol 474, 504-523 (2004).

13. Flames, N., et al. Delineation of multiple subpallial progenitor domains by the combinatorial expression of transcriptional codes. J Neurosci 27, 9682-9695 (2007).

14. García-López, M., et al. Histogenetic compartments of the mouse centromedial and extended amygdala based on gene expression patterns during development. J Comp Neurol 506, 46-74 (2008).

15. Canteras, N.S., Simerly, R.B. \& Swanson, L.W. Organization of projections from the medial nucleus of the amygdala: a PHAL study in the rat. J Comp Neurol 360, 213-245 (1995).

16. Stenman, J., Toresson, H. \& Campbell, K. Identification of two distinct progenitor populations in the lateral ganglionic eminence: implications for striatal and olfactory bulb neurogenesis. J Neurosci 23, 167-174 (2003). 
17. Wang, W. \& Lufkin, T. The murine Otp homeobox gene plays an essential role in the specification of neuronal cell lineages in the developing hypothalamus. Dev Biol 227, 432-449 (2000).

18. Bardet, S.M., Martínez-de-la-Torre, M., Northcutt, R.G., Rubenstein, J.L.R. \& Puelles, L. Conserved pattern of OTP-positive cells in the paraventricular nucleus and other hypothalamic sites of tetrapods. Brain Res Bull 75, 231-235 (2008).

19. Michaud, J.L., Rosenquist, T., May, N.R. \& Fan, C.M. Development of neuroendocrine lineages requires the bHLH-PAS transcription factor SIM1. Genes Dev 12, 3264-3275 (1998).

20. Nakai, S., et al. The POU domain transcription factor Brn-2 is required for the determination of specific neuronal lineages in the hypothalamus of the mouse. Genes Dev 9, 3109-3121 (1995).

21. Fan, C.M., et al. Expression patterns of two murine homologs of Drosophila singleminded suggest possible roles in embryonic patterning and in the pathogenesis of Down syndrome. Mol Cell Neurosci 7, 1-16 (1996).

22. Sheng, H.Z., et al. Expression of murine Lhx5 suggests a role in specifying the forebrain. Dev Dyn 208, 266-277 (1997).

23. Puelles, L. \& Rubenstein, J.L.R. Forebrain gene expression domains and the evolving prosomeric model. Trends Neurosci 26, 469-476 (2003).

24. Simeone, A., et al. Orthopedia, a novel homeobox-containing gene expressed in the developing CNS of both mouse and Drosophila. Neuron 13, 83-101 (1994).

25. Acampora, D., Postiglione, M.P., Avantaggiato, V., Bonito, M.D. \& Simeone, A. The role of Otx and Otp genes in brain development. Int J Dev Biol 44, 669-677 (2000).

26. Blechman, J., et al. Specification of hypothalamic neurons by dual regulation of the homeodomain protein Orthopedia. Development 134, 4417-4426 (2007).

27. Acampora, D., et al. Progressive impairment of developing neuroendocrine cell lineages in the hypothalamus of mice lacking the Orthopedia gene. Genes Dev 13, 2787-2800 (1999).

28. Ryu, S., et al. Orthopedia homeodomain protein is essential for diencephalic dopaminergic neuron development. Curr Biol 17, 873-880 (2007).

29. Altman, J., Bayer, S. A. Development of the diencephalon in the rat. I. Autoradiographic study of the time of origin and settling patterns of neurons of the hypothalamus. $J$ Comp Neurol 182, 945-71 (1978a).

30. Altman, J., Bayer, S. A. Development of the diencephalon in the rat. II. Correlation of the embryonic development of the hypothalamus with the time of origin of its neurons. J Comp Neurol 182, 973-93 (1978b).

31. Swanson, L. W. Development of the paraventricular nucleus of the hypothalamus. in: From development to degeneration and regeneration of the nervous system (eds. Ribak, C. E., Arámburo-de la Hoz, C., Jones, E. G., Larriva-Sahd, J. A. \& Swanson, L. W.) 69-84 (Oxford Univ. Press, Oxford, UK, 2009).

32. Choi, G.B., Dong, H.W., Murphy, A.J., Valenzuela, D.M., Yancopoulos, G.D., Swanson, L.W. \& Anderson, D.J. Lhx6 delineates a pathway mediating innate reproductive behaviors from the amygdala to the hypothalamus. Neuron 46, 647-60 (2005).

33. Letinic, K. \& Rakic, P. Telencephalic origin of human thalamic GABAergic neurons. Nat Neurosci 4, 931-936 (2001). 
34. Rakic, P. Principles of neural cell migration. Experientia 46, 882-891 (1990).

35. De Carlos, J.A., López-Mascaraque, L. \& Valverde, F. Dynamics of cell migration from the lateral ganglionic eminence in the rat. J Neurosci 16, 6146-6156 (1996).

36. Anderson, S., Mione, M., Yun, K. \& Rubenstein, J.L. Differential origins of neocortical projection and local circuit neurons: role of Dlx genes in neocortical interneuronogenesis. Cereb Cortex 9, 646-654 (1999).

37. Lavdas, A.A., Grigoriou, M., Pachnis, V. \& Parnavelas, J.G. The medial ganglionic eminence gives rise to a population of early neurons in the developing cerebral cortex. J Neurosci 19, 7881-7888 (1999).

38. Wichterle, H., Turnbull, D.H., Nery, S., Fishell, G. \& Alvarez-Buylla, A. In utero fate mapping reveals distinct migratory pathways and fates of neurons born in the mammalian basal forebrain. Development 128, 3759-3771 (2001).

39. Zhao, T., et al. Genetic mapping of Foxb1-cell lineage shows migration from caudal diencephalon to telencephalon and lateral hypothalamus. Eur J Neurosci 28, 19411955 (2008).

40. Soma, M., et al. Development of the mouse amygdala as revealed by enhanced green fluorescent protein gene transfer by means of in utero electroporation. J Comp Neurol 513, 113-128 (2009).

41. Hirata, T., et al. Identification of distinct telencephalic progenitor pools for neuronal diversity in the amygdala. Nat Neurosci 12, 141-149 (2009).

42. Remedios, R., Subramanian, L. \& Tole, S. LIM genes parcellate the embryonic amygdala and regulate its development. J Neurosci 24, 6986-6990 (2004).

43. García-Moreno, F., López-Mascaraque, L. \& De Carlos, J.A. Early telencephalic migration topographically converging in the olfactory cortex. Cereb Cortex 18,12391252 (2008).

44. Caqueret, A., Boucher, F. \& Michaud, J.L. Laminar organization of the early developing anterior hypothalamus. Dev Biol 298, 95-106 (2006).

45. García-Moreno, F., López-Mascaraque, L. \& De Carlos, J.A. Origins and migratory routes of murine Cajal-Retzius cells. J Comp Neurol 500, 419-432 (2007).

46. Valverde, F. The Golgi method. A tool for comparative structural analyses. in: Contemporary research methods in Neuroanatomy (eds. Nauta, W.J.H., Ebbensson, S.O.E.) 12-31 (Springer, New York, USA, 1970). 


\section{E10}

E11

E12

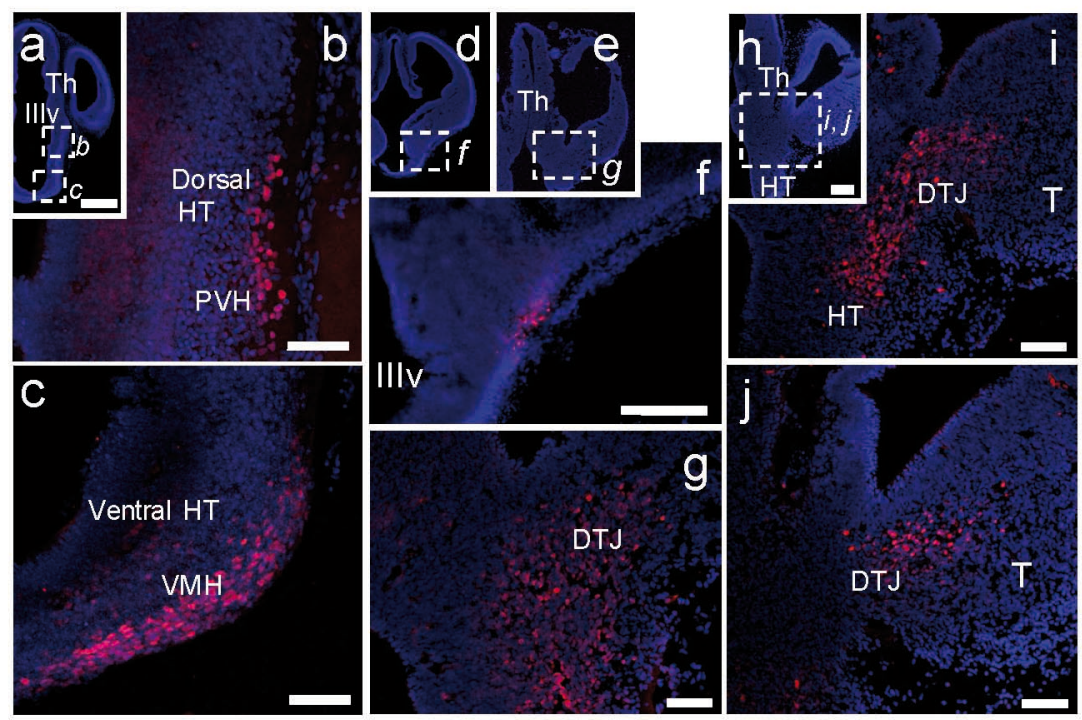

\section{E15}

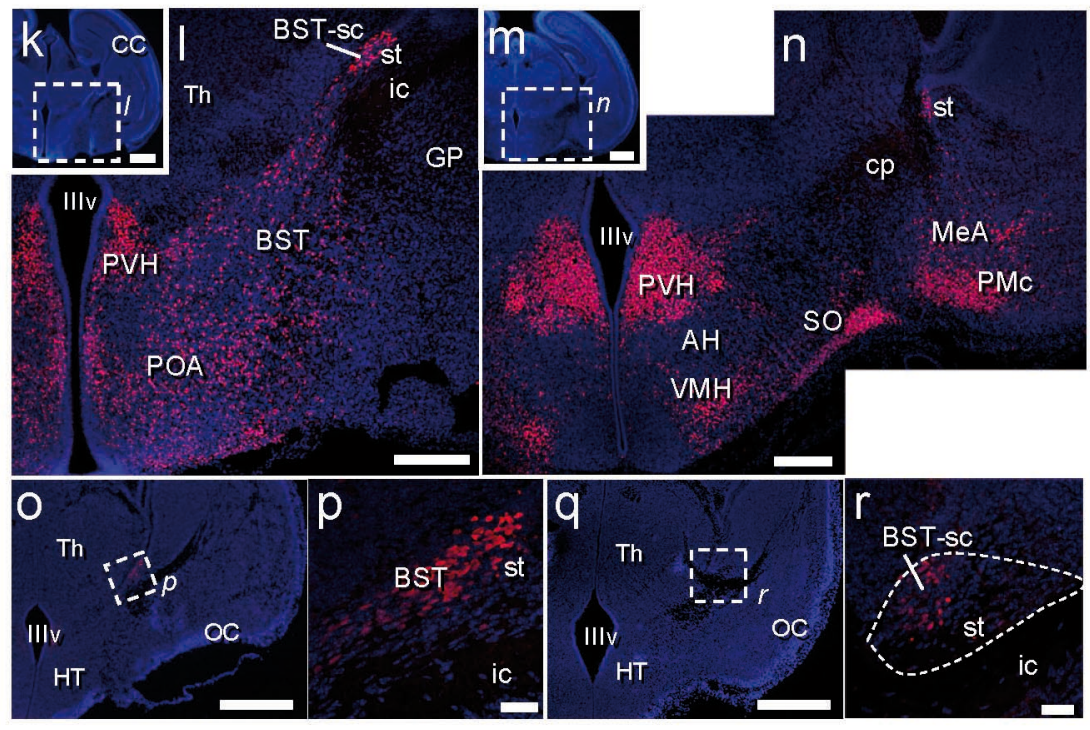

\section{E18}

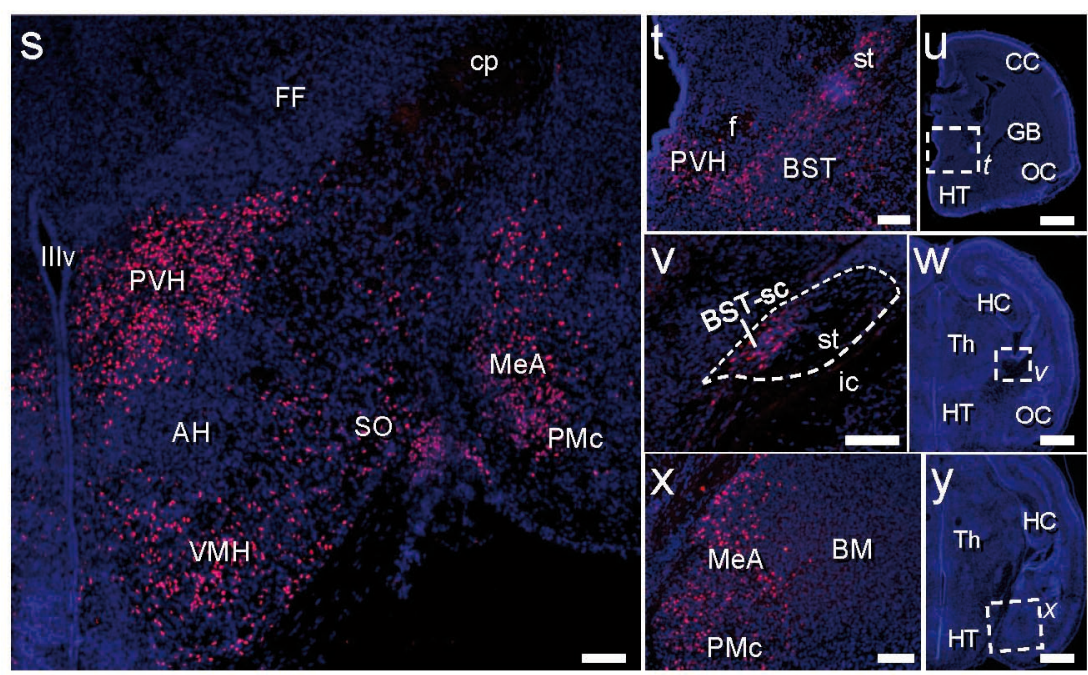



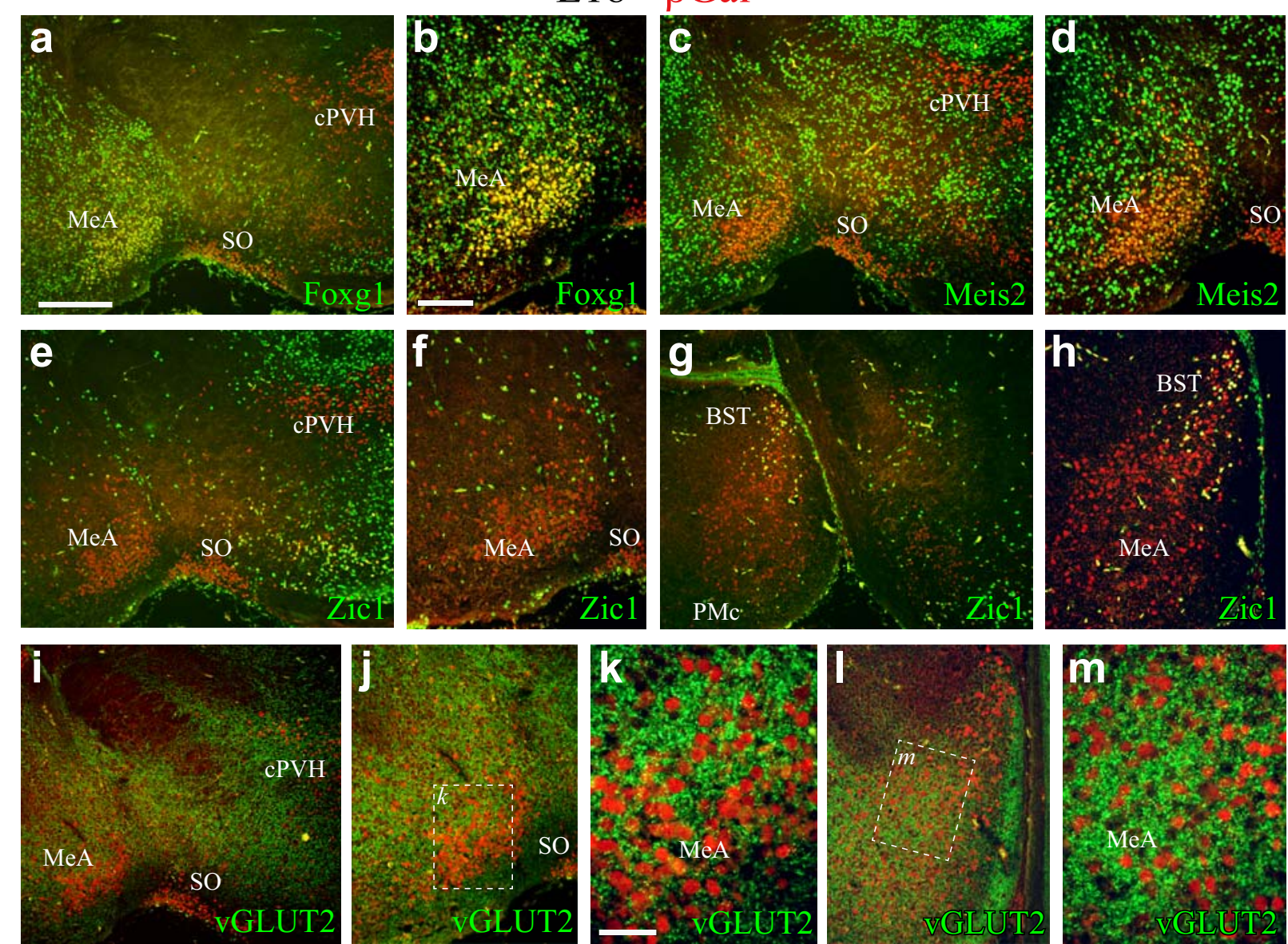

Cellular morphology

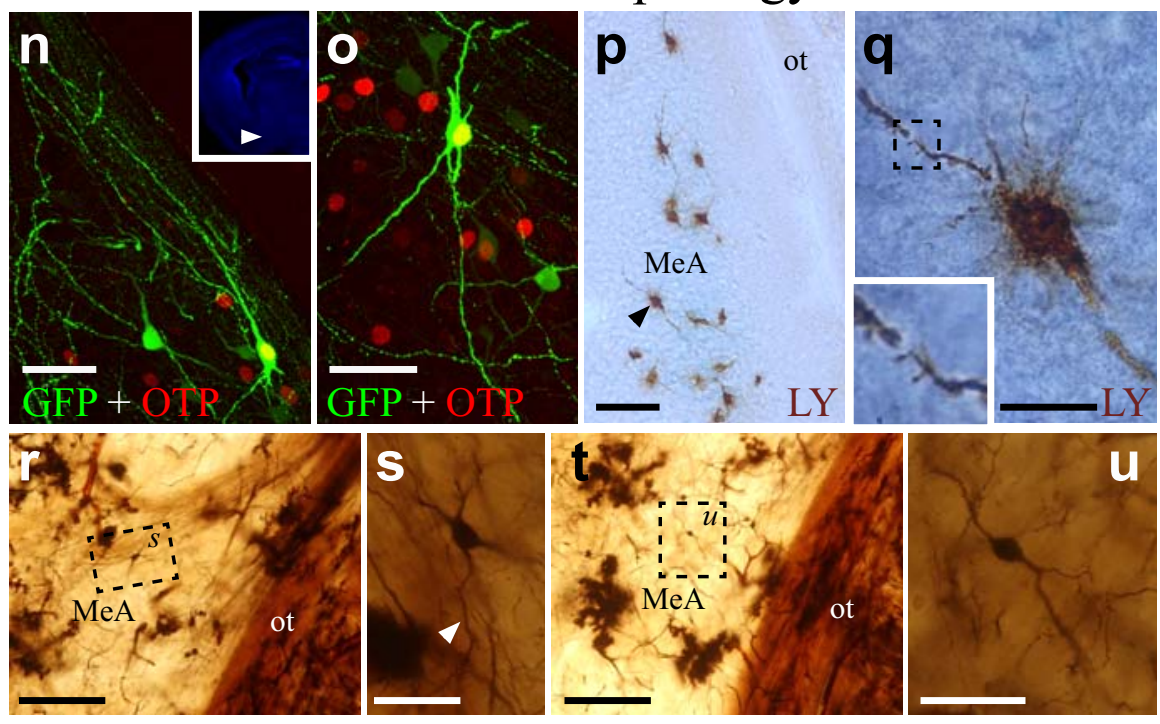



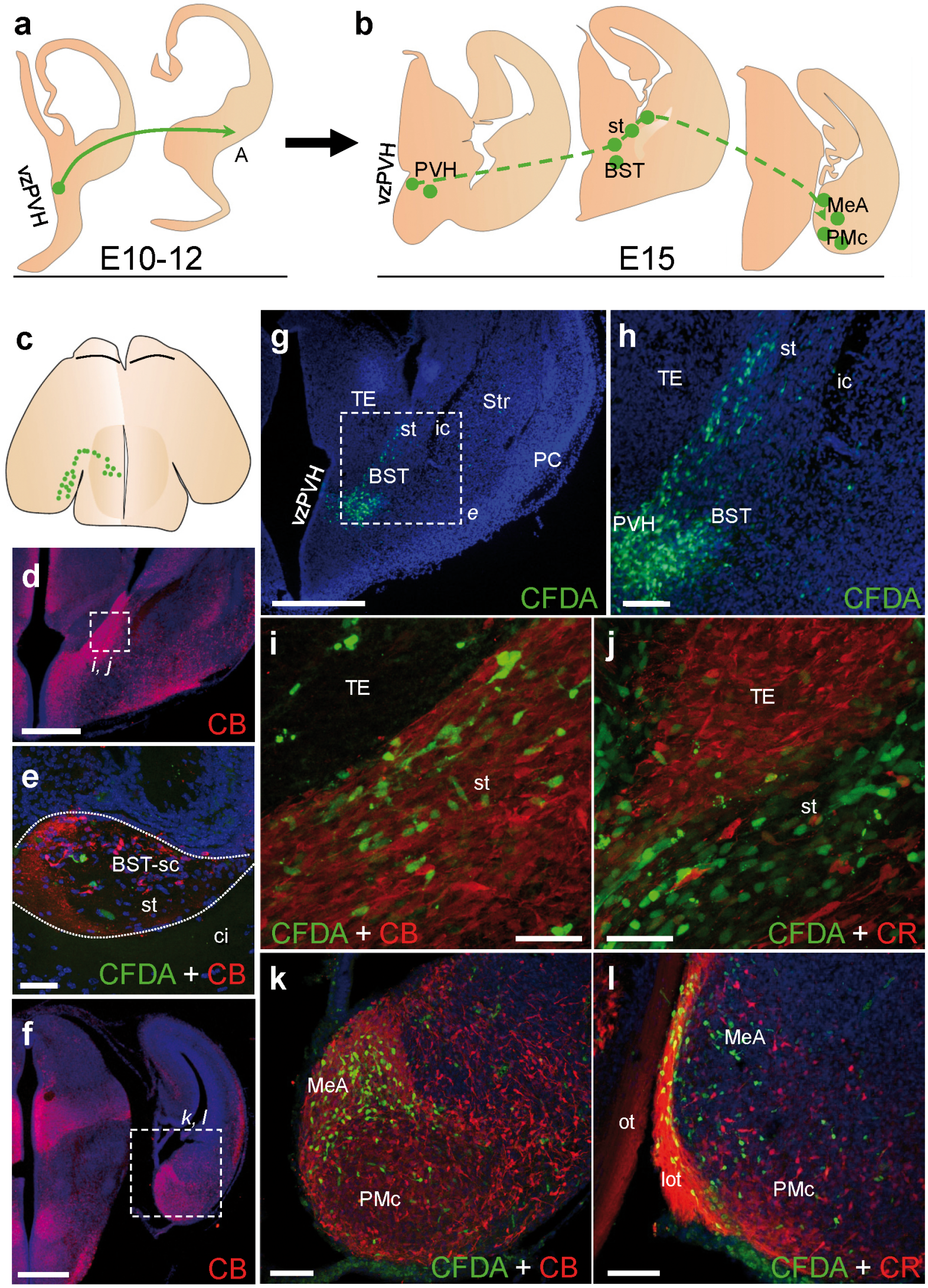


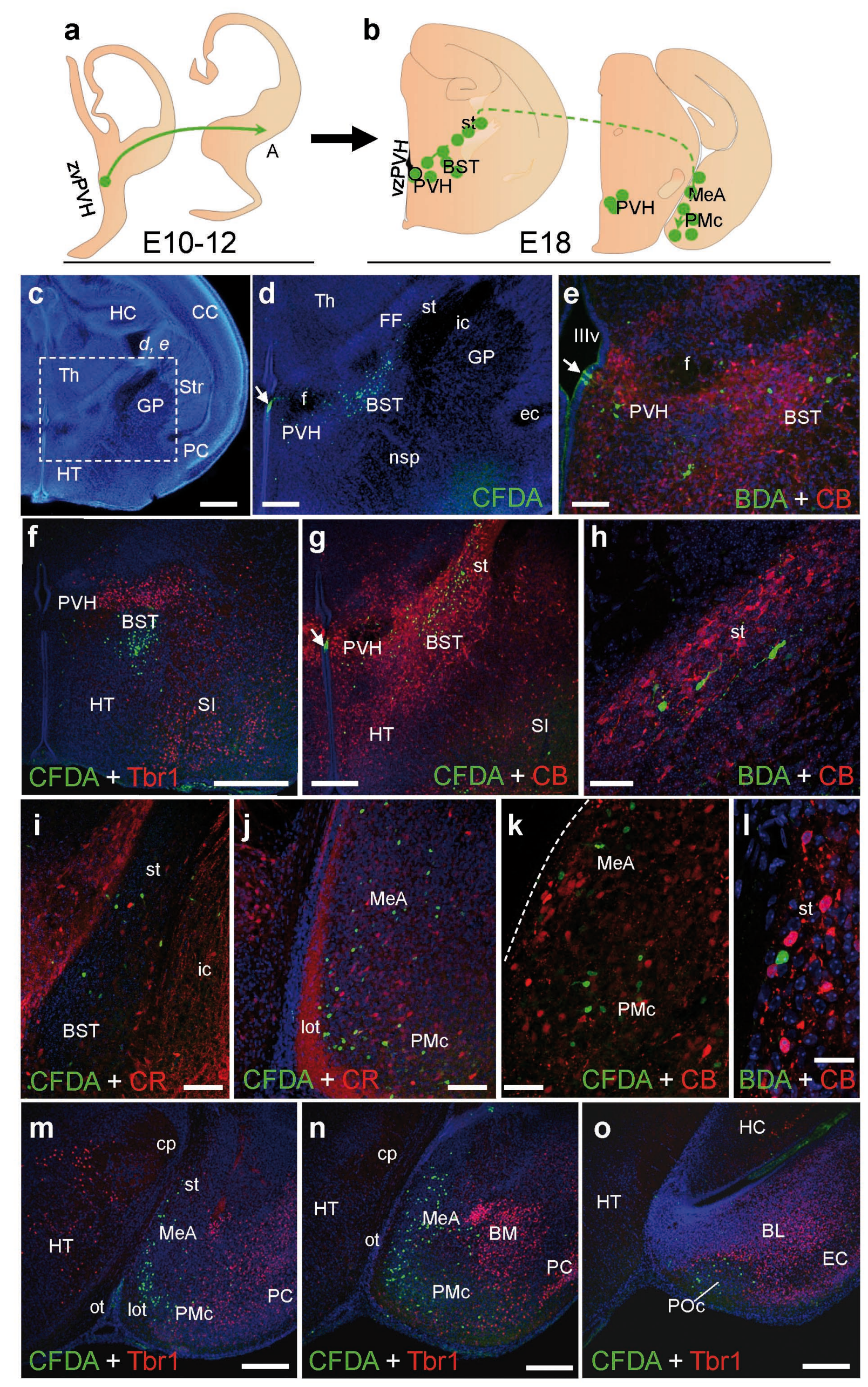




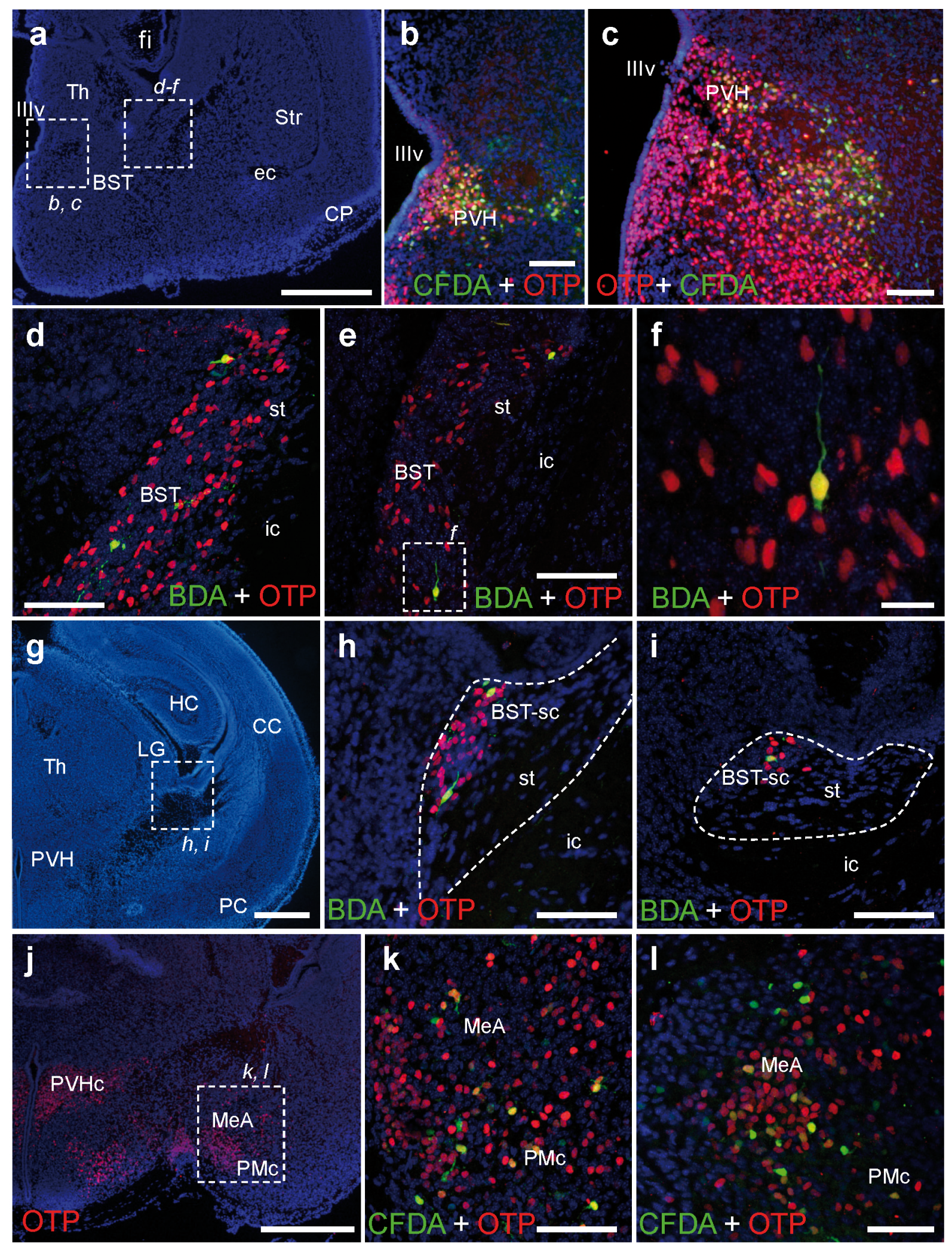




\section{GFP (E10) + OTP (E18)}
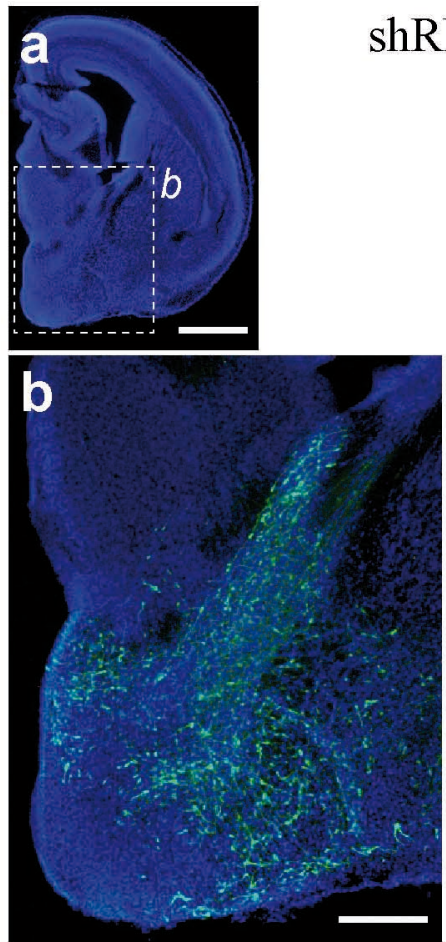

e

PMc

m Hypothalamus

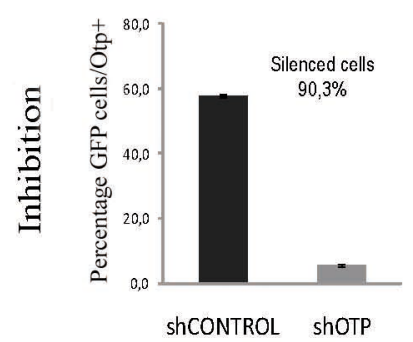

shRNA-control

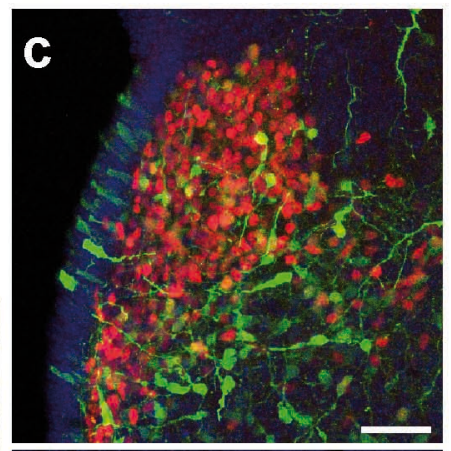

do
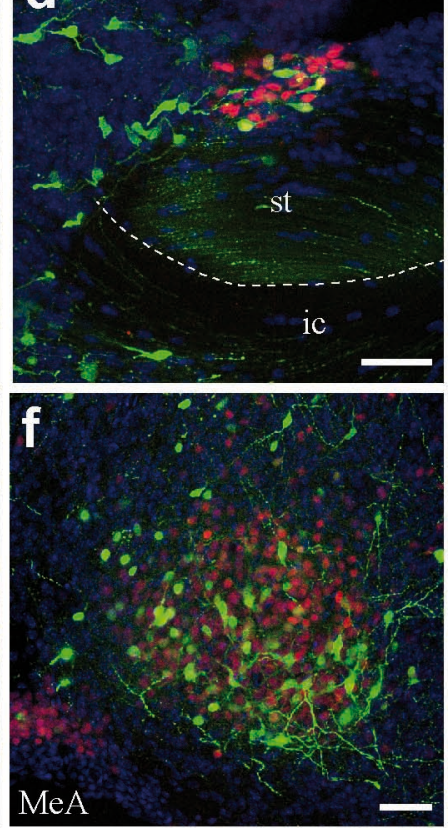

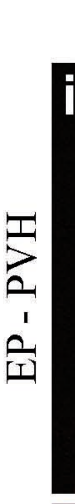

j
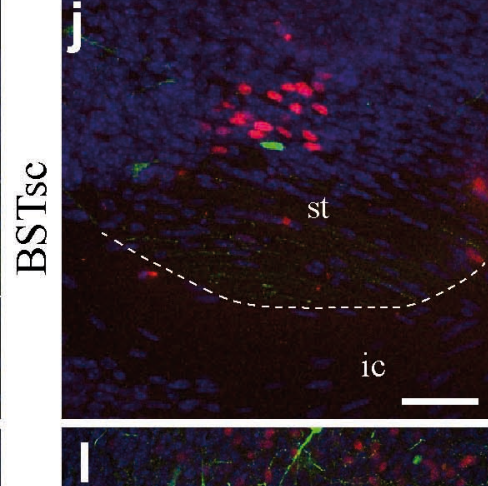

shRNA-Otp
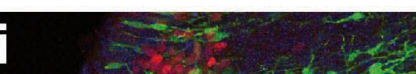

9
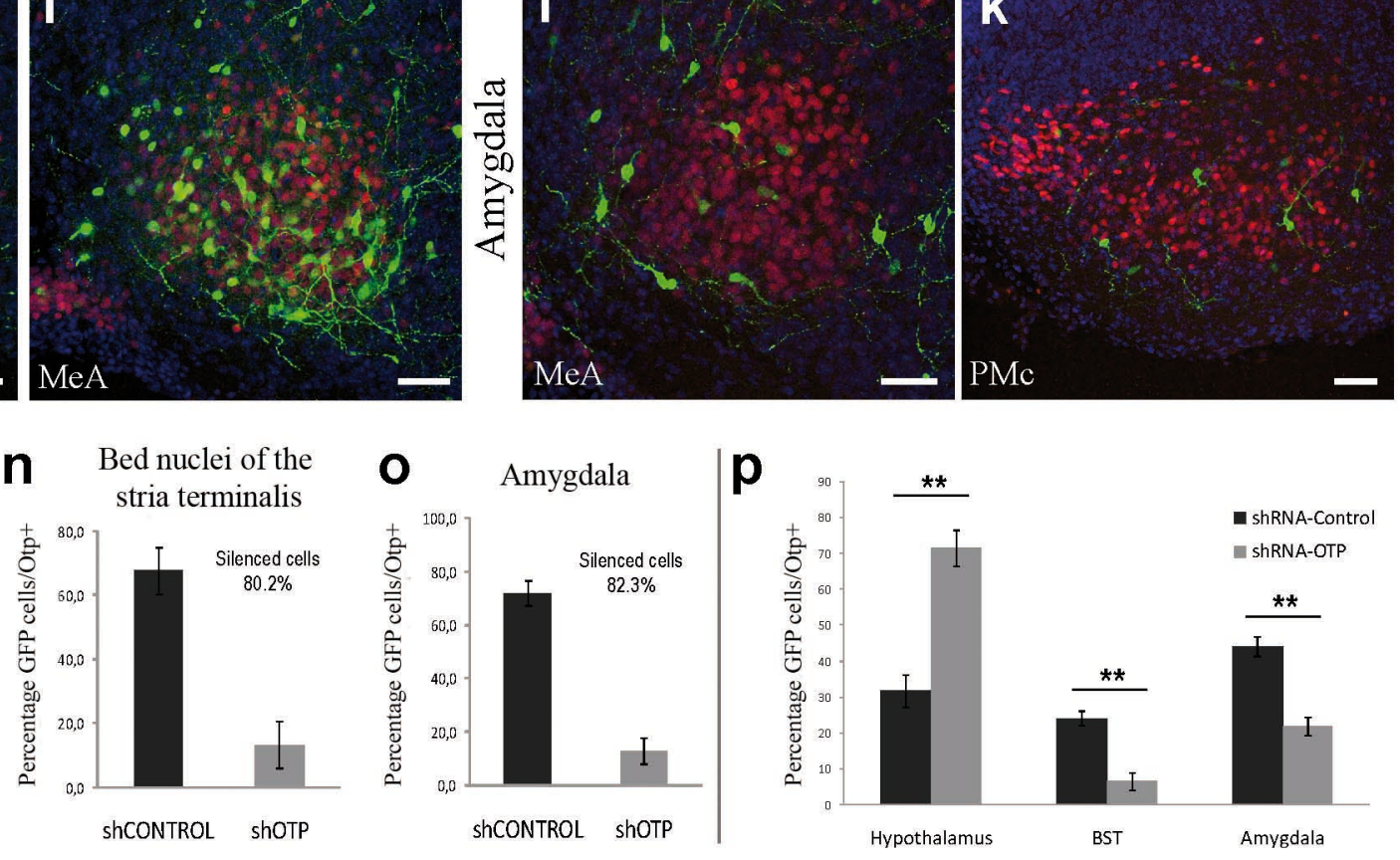
Otp +/- E1S-pGall Otp -/-
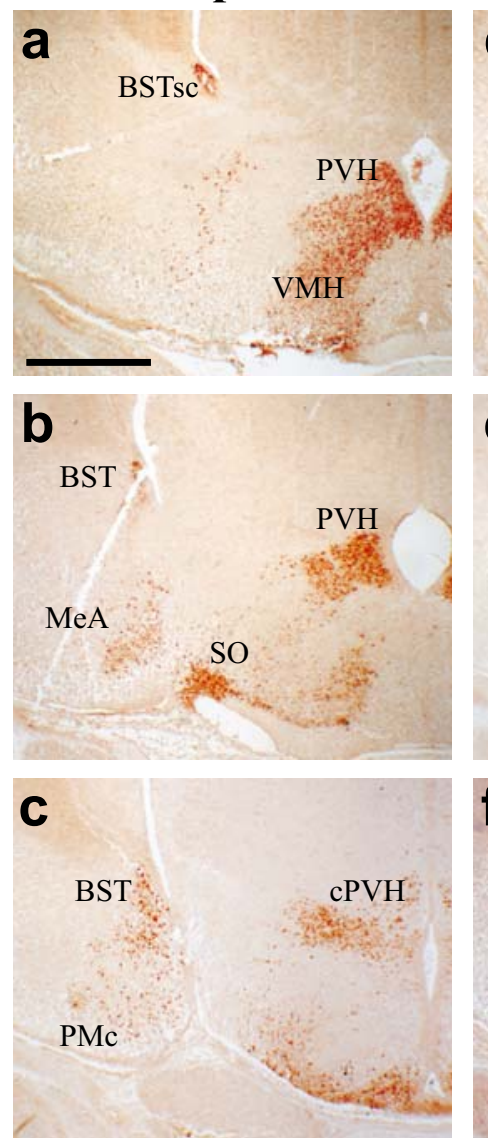
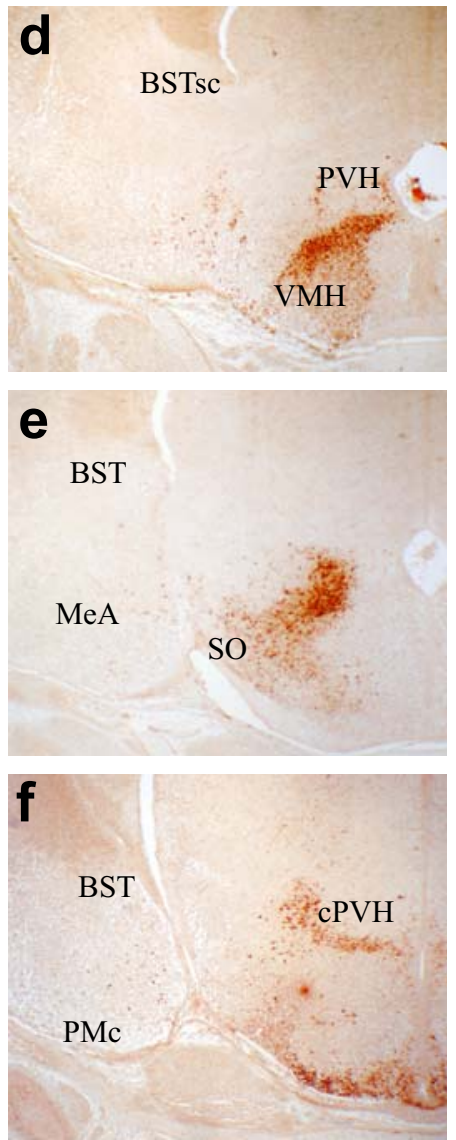

Otp +/- EI8-pGal Otp -/-
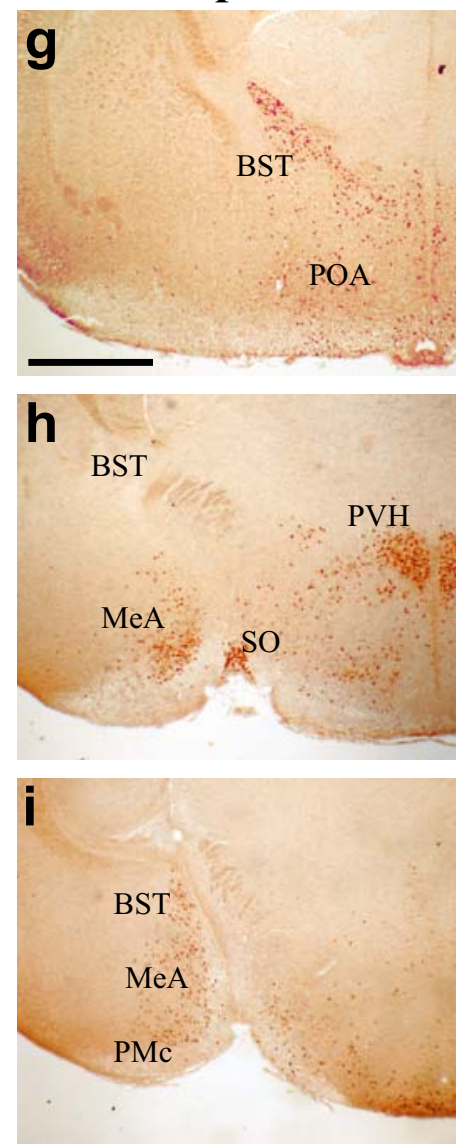
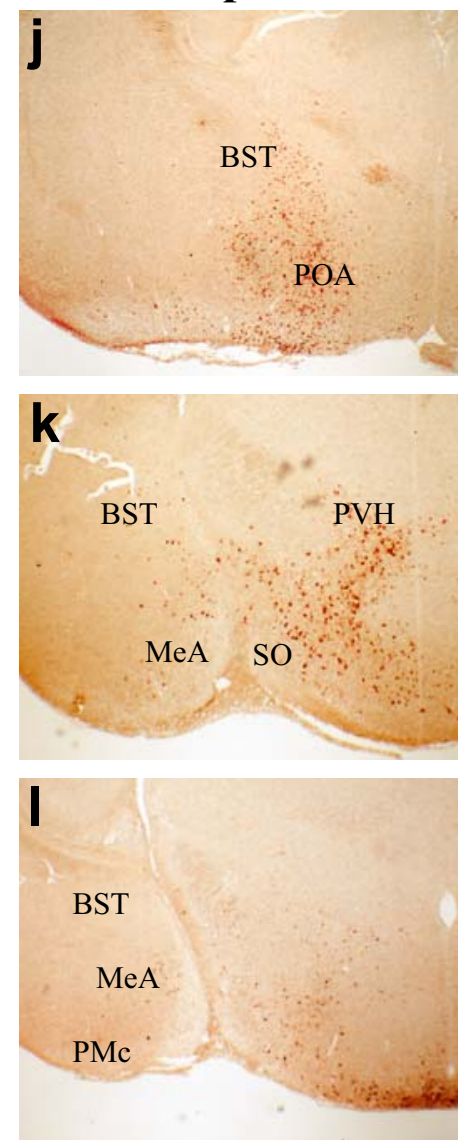
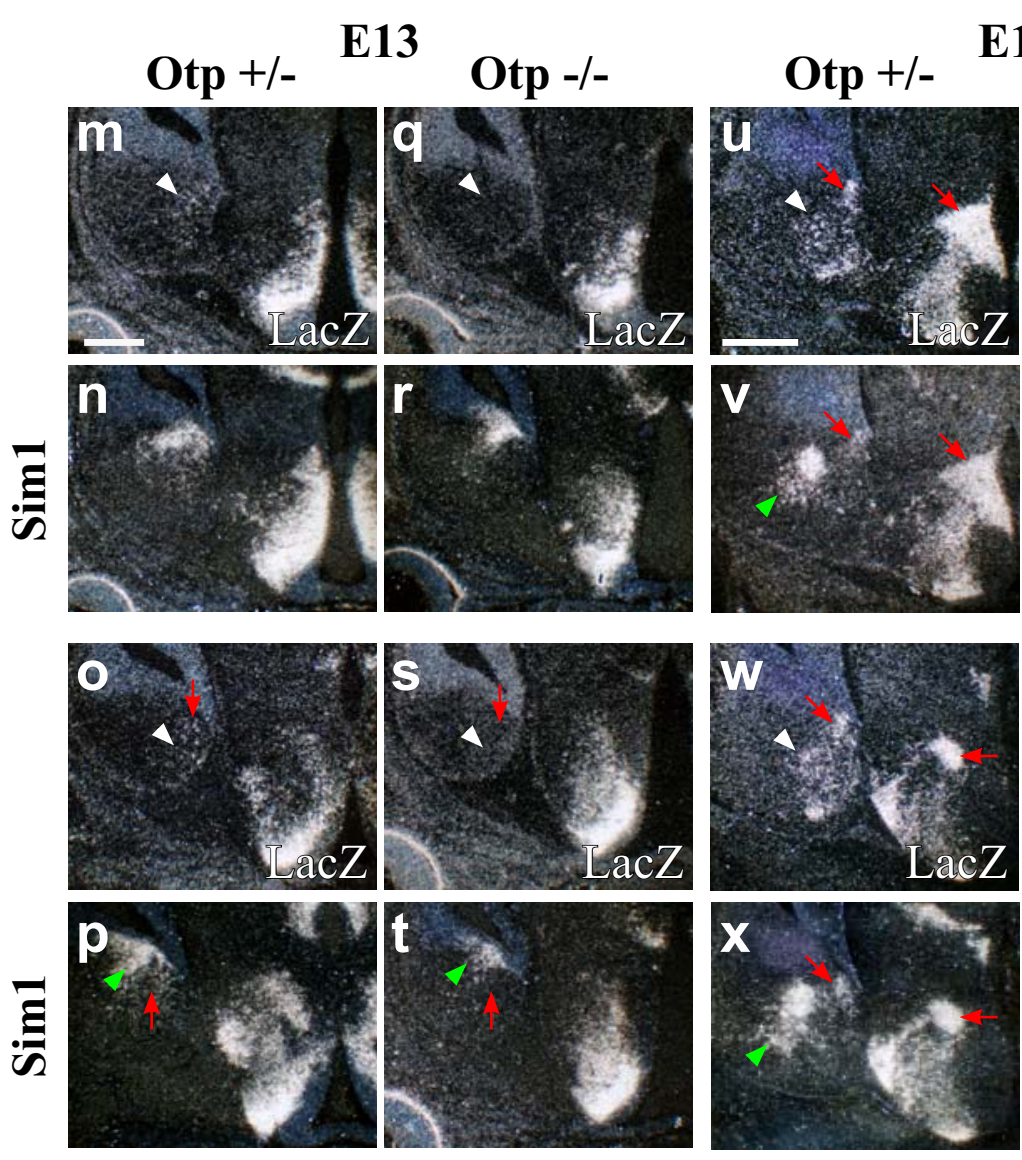

E15
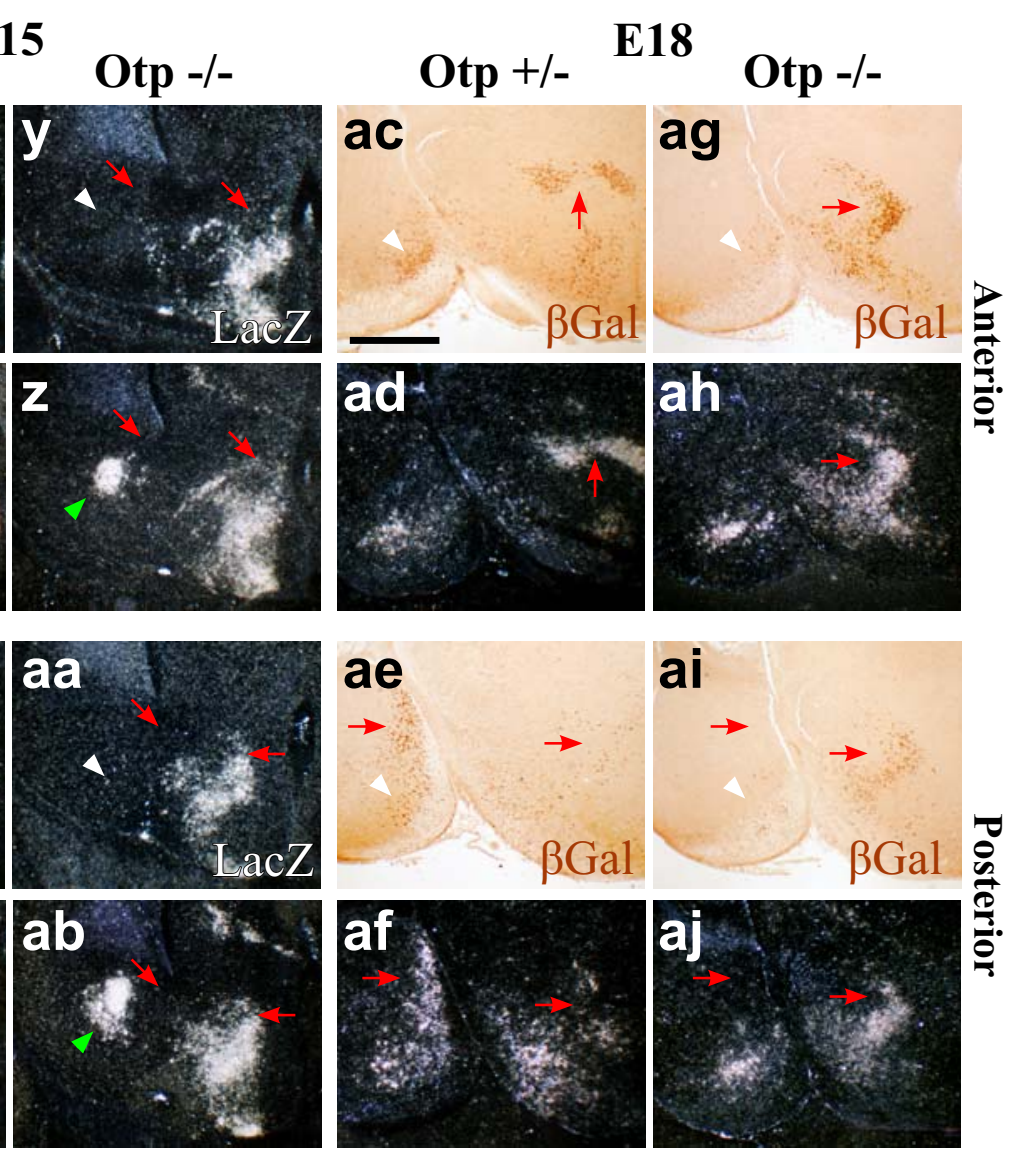

ai

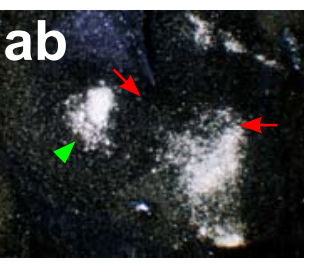

a)

BGal

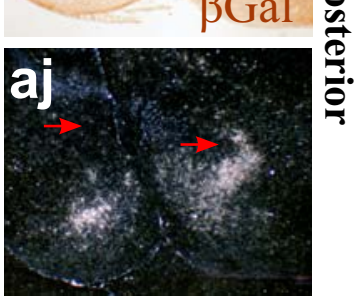




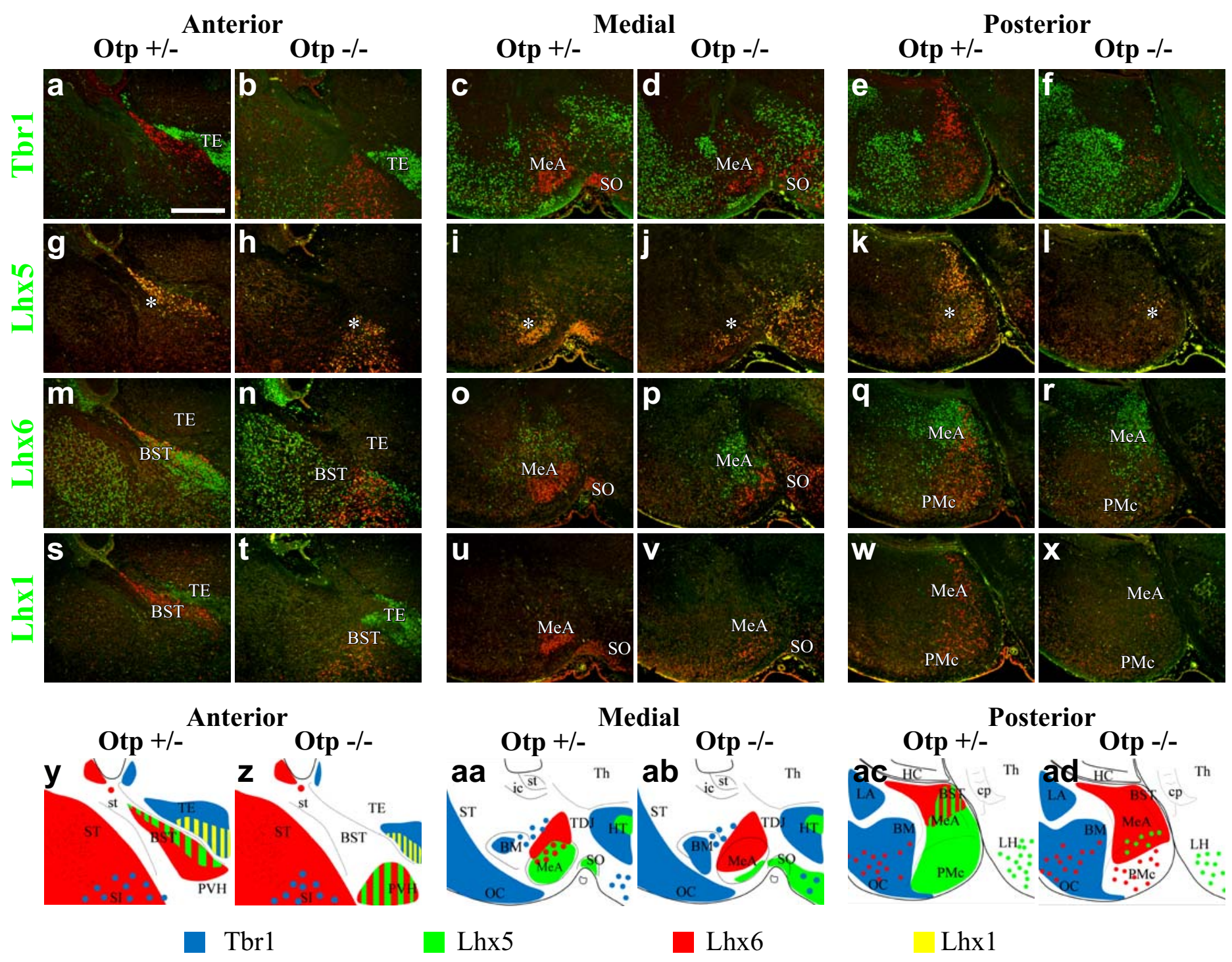

